بروسى نقش ترازهاى واقعى يول در تابع ترجيحات خانوار با جار جوب تعديل شده مدل قيمت كذارى دارايى هاى سرمايه اى (M-CCAPM): مطالعه موردى ايران رضا روشن

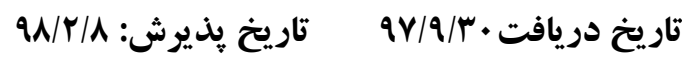

جكيده

در اين مقاله به بررسى نقش ترازهاى واقعى يول در تابع ترجيحات خانوار با جار جوب

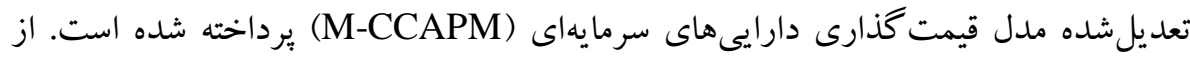

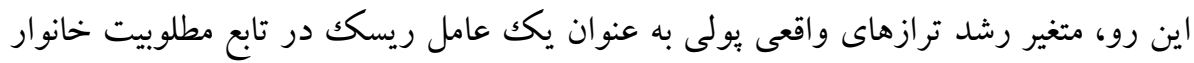

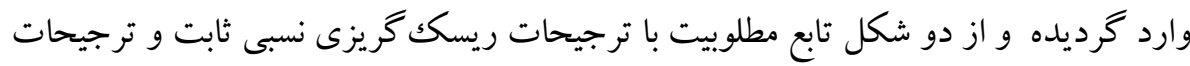

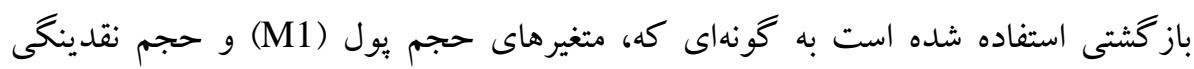
(مجموع يول و شبه يول)، (M2) به عنوان ورودى در تابع مطلوبيت در نظر خرفته شده است. بس از تخمين سيستمهاى معادلات اولر استخراجى با روش گشتاورهاى تعميم يافته، با استفاده از معيارهاى MAE و MSE به انتخاب مناسب ترين مدل بر آورد كننده سهم متغير تراز

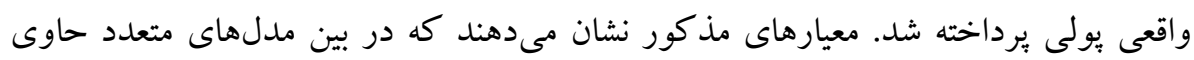

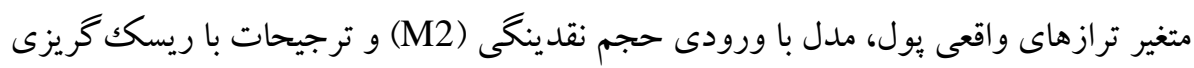

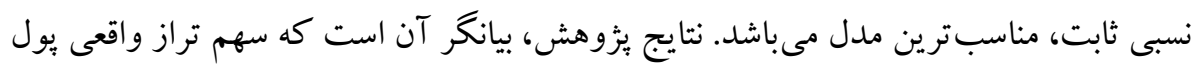

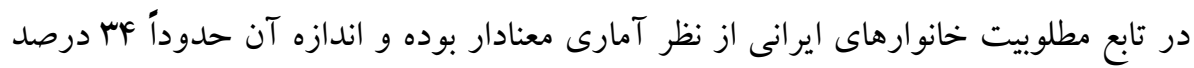

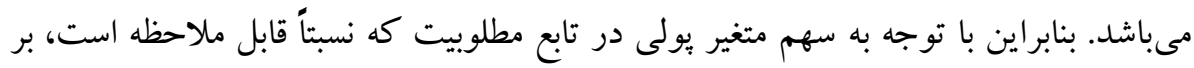

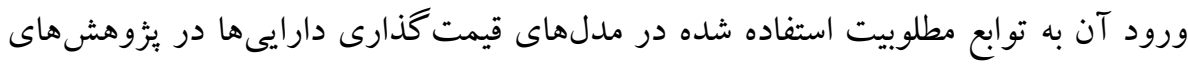
مختلف، تاكيد مى گر مدرد.

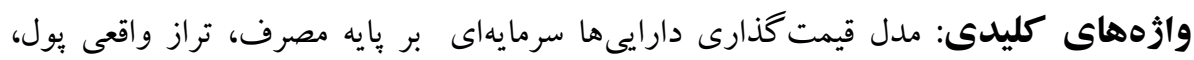

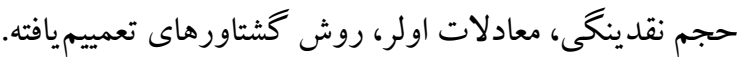
طبقهبندى J12, E50, E3, C52 :JEL.

Email:re.roshan@pgu.ac.ir .ا استاديار كروه اقتصاد دانشكده ادبيات و علوم انسانى دانشكاه خليج فارس، بوشهر (نويسنده مسئول) 
1. مقدمه

به تبعيت از كار كلاسيكك مرتن ( (19VI)، اغلب مقالاتى كه بِ از وى به مطالعه در

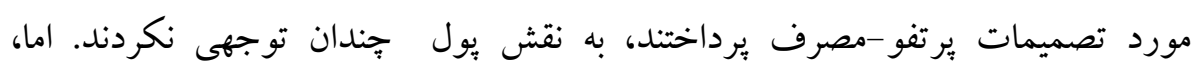

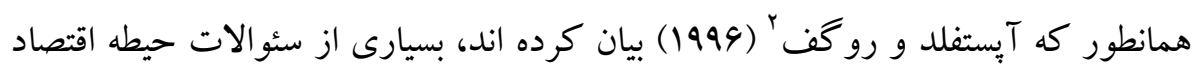

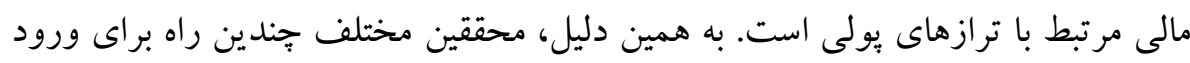

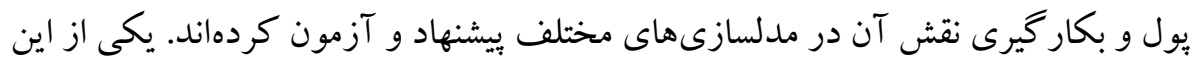
راهها كه تمركز ئزوهش حاضر نيز بر آن است، ورود يول به تابع مطلوبيت مىباشد كه

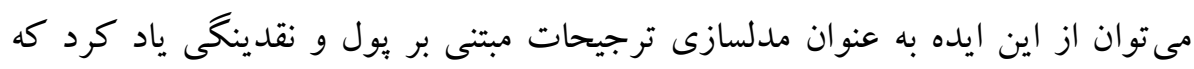

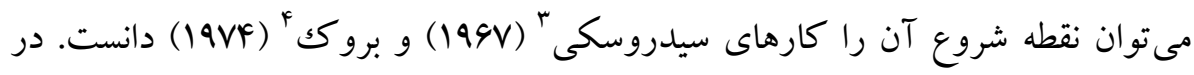

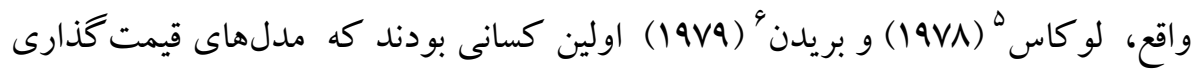
دارايى بر بايه مصرف (CCAPM

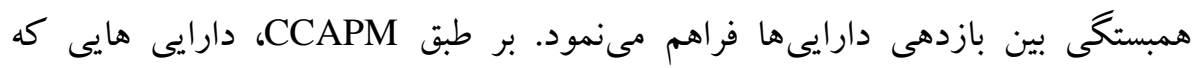

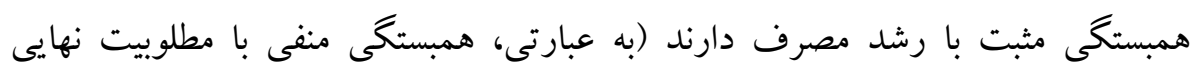

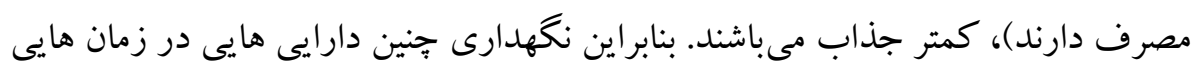
كه مصرف يايين بوده (كه به تبع آن مطلوبيت نهايى مصرف بالاست) مطلوب نمىباشد؛ از

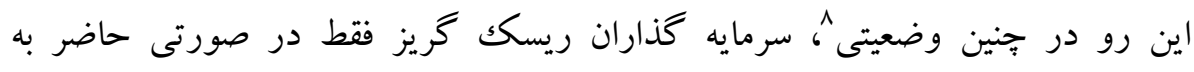

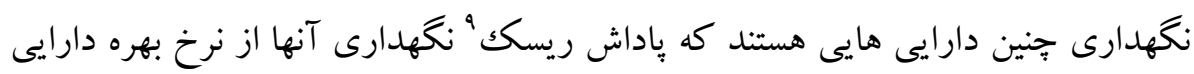

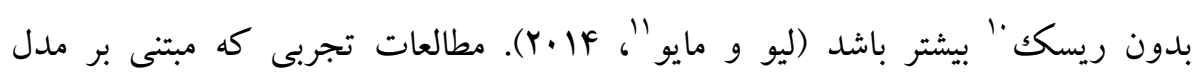

1. Merton

2. Obstfeld and Rogoff

3. Sidrauski

4. Brock

5. lucas

6. Breeden

7. Consumption Asset Pricing Model

8. bad states

9. risk premium

10. risk-free rate

11. Lioui and Maio 
استاندارد CCAPM و بريايه مطلوبيت توانى براى تبين بازدهى دارايىها و هم:جنين

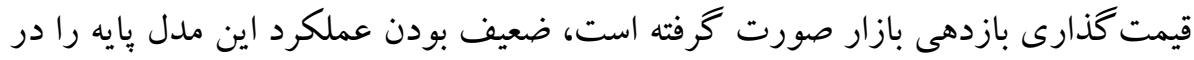

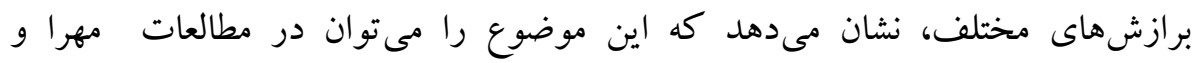

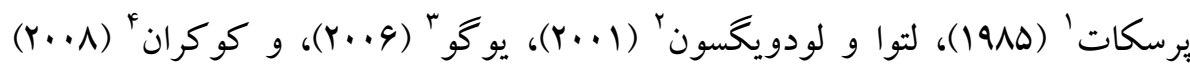
مشاهده نمود. هدف محورى در مقاله حاضر اين است كه با استفاده از ورود متغير تراز يولى به تابع مطلوبيت مصرف كننده نوعى و استفاده از ترجيحات مختلف در تابع مطلوبيت، ضمن توسعه مدل استاندارد CCAPM، سهم تراز واقعى بول در تابع ترجيحات

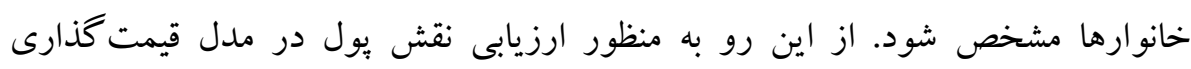
دارايىها در قالب يكك معادله اولر، ابتدا با ورود متغير يولى در تابع مطلوبيت با ريسك روك

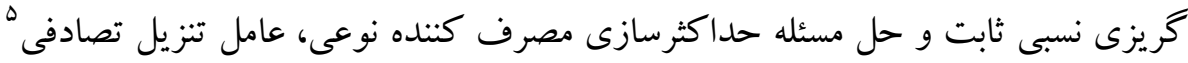
حاوى متغيرهاى مصرف و تراز واقعى يول را بدست آورده و معادله اولر نظير آن را استخر اج مى شود؛ سيس، با استفاده از ترجيحات باز گشتى إستين و زين (1991) در تابع مطلوبيت و ورود متغير تراز يولى در آن، به حل مسئله مصرف كننده نوعى در اين حالت يرداخته و ضمن تعيين عامل تنزيل تصادفى براى اين مسئله، معادله اولر آن نيز استخراج مى گردد. از آنجايى كه هدف اصلى يزوهش حاضر، بر آورد سهم متغير تراز واقعى يول در تابع

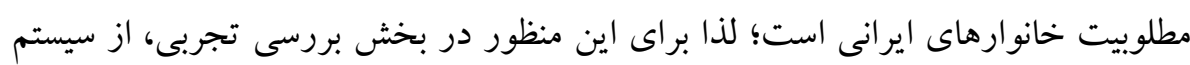

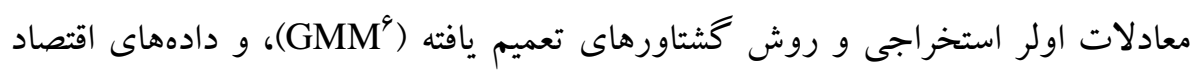

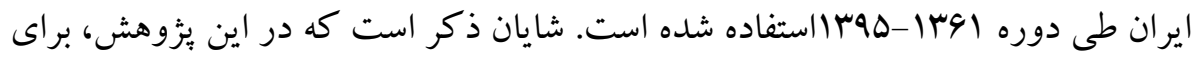
متغير تراز واقعى يول از دو متغير حجم يول (مجموع اسكناس و مسكو كات در دست مردم

1. Mehra and Prescott

2. Lettau and Ludvigson

3. Yogo

4. Cochrane

5. Stochastic Discount Factor

6. Generalized method of moments 


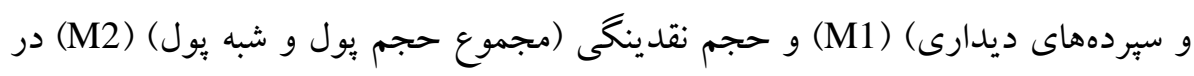

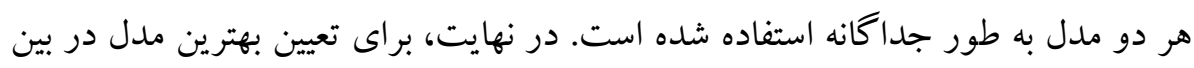

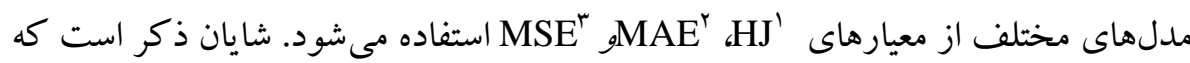
نو آورى مقاله حاضر نسبت به مطالعات بيشين كه در داخل كشور انجام شده، در اين است

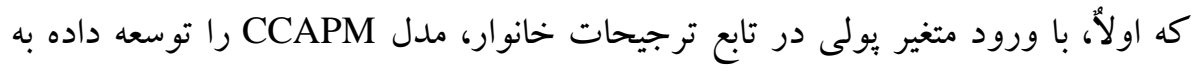

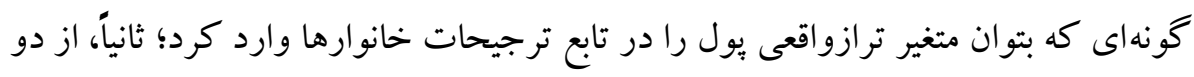
نوع ترجيحات با ريسك گريزى نسبى ثابت و ترجيحات باز گشتى در تابع مطلوبيت

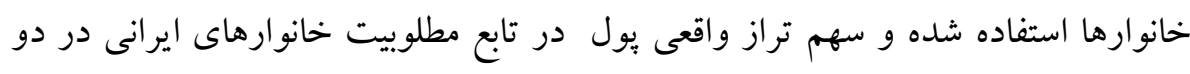

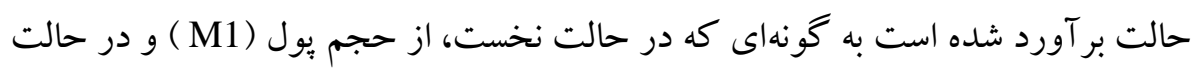
دوم از حجم نقدينكى (M2) به عنوان متغير تراز واقعى بول استفاده شده است. ثالثاً، در اين

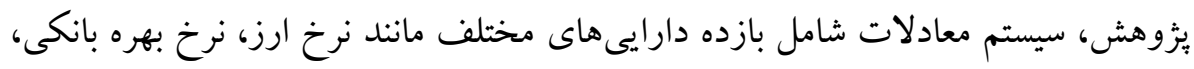

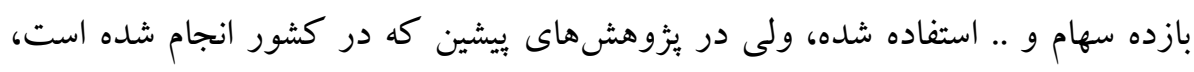

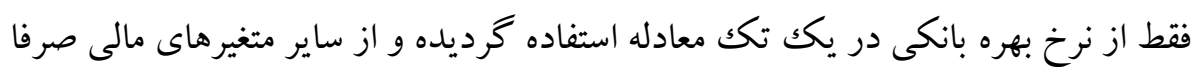
به عنوان متغيرهاى ابزارى استفاده شده است. فر آيند مدلسازى در بخش بيان مدل تحقيق

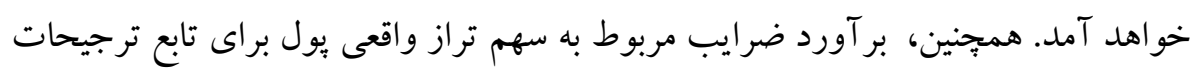

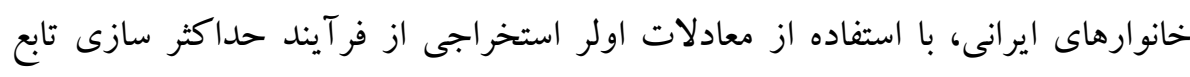
مطلوبيت و بكار گيرى رهيافت GMM، در قسمت بررسى تجربى ارايه خواهد شد.

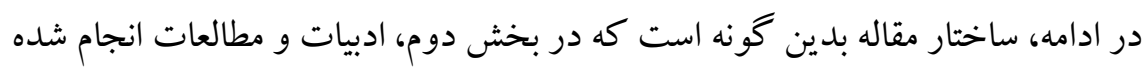

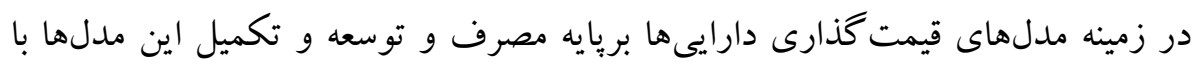
تاكيد بر تراز واقعى بولى مرور مىشود. در بخش سوم، مبانى نظرى و مدلهاى دو كانهى

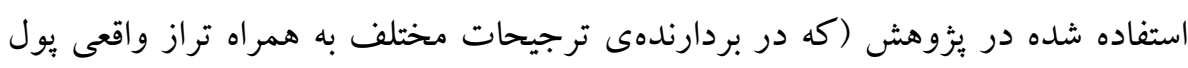

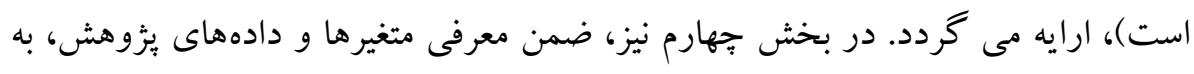

1. Hansen-Jagannathan

2. Mean Absolute Errors

3. Mean Sum Squared Errors 
كمكك معادلات اولر استخراجى به تخمين سهم تراز واقعى يول در تابع مطلوبيت

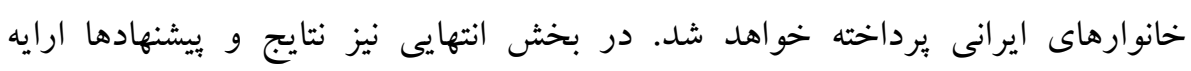
مى گردد.

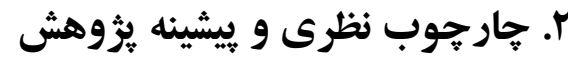

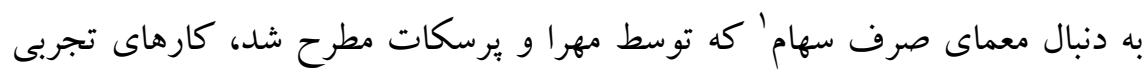

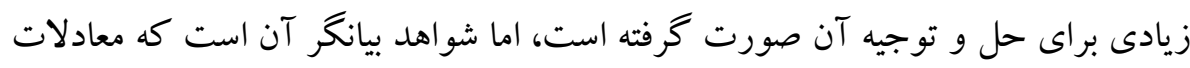

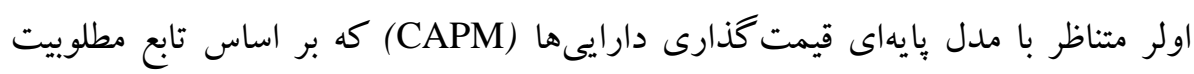

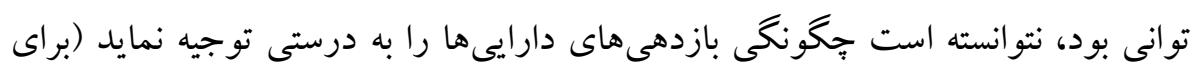

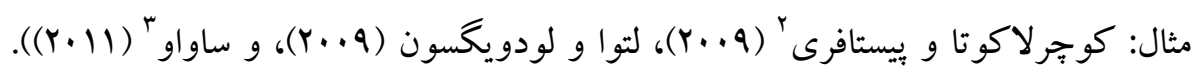
بعلاوه، رشد ادبيات مربوطه بيانگر آن است كه نسخه خطى مدل قيمت گذارى دارايىها بر

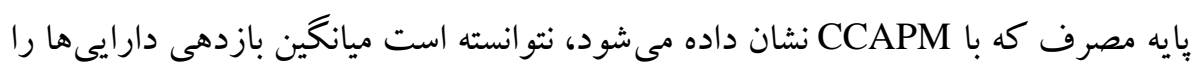

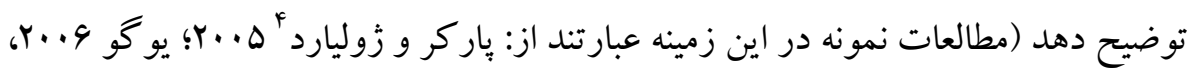

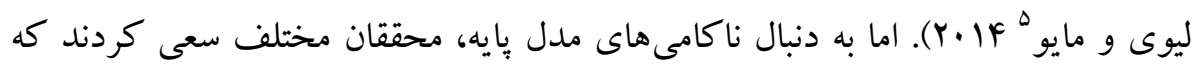
علاوه بر متغير رشد مصرف، با اضافه كردن متغيرهاى كلان ديخرى (به عنوان عوامل

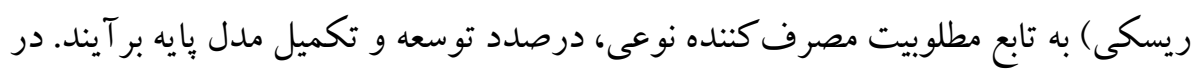

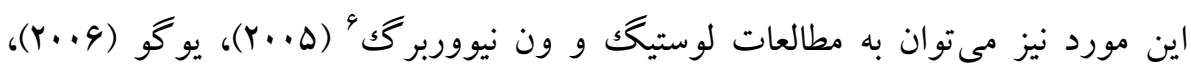

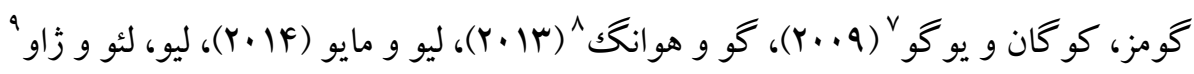

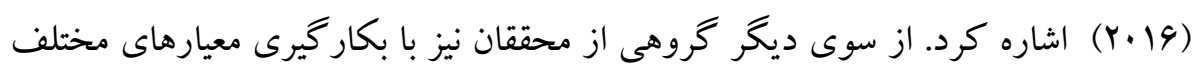

1. Equity Premium Puzzle

2. Kocherlakota and Pistaferri

3. Savov

4. Parker and Julliard

5. Lioui and Maio

6. Lustig and Van Nieuwerburgh

7. Gomes, Kogan, and Yogo

8. Gu, L., and D. Huang

9. Liu, Luo, and Zhao 
جايخزين براى رشد مصرف در تابع مطلوبيت، به بررسى عملكرد مدلهاى قيمت گذارى

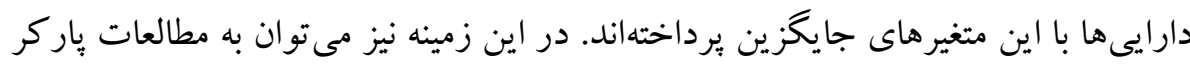

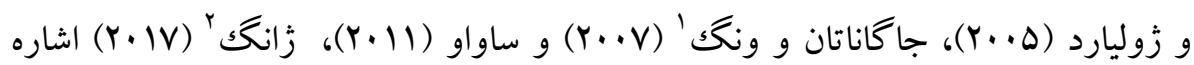

مىتوان بيان داشت كه در بين كارهاى تجربى انجام شده براى تكميل و ارتقاء

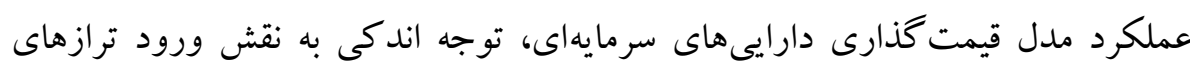
واقعى يول در توابع مختلف ترجيحات استفاده شده در جارجوب CCAPM شده است. از اين رو، مطالعه حاضر درصدد است تا اين خلاً را بر نموده و با استفاده از دادههاى اقتصاد

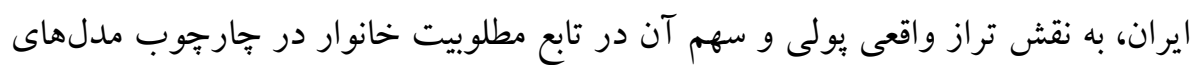

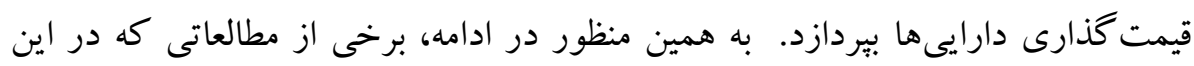
زمينه انجام شده است، مرور مى گردد.

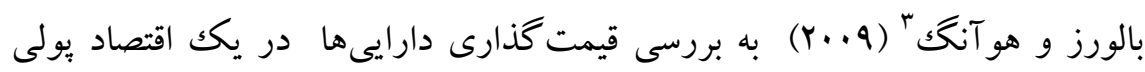
يرداختند به طورى كه فرض نمودند كه عاملان اقتصادى براى كاهش هزينه هاى انتقال، به نخهدارى دارايىهاى نقد مبادرت مىورزند. آنان مدل قيمت گذذارى دار ييهاى سرمايهاى

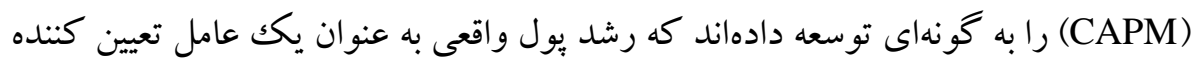

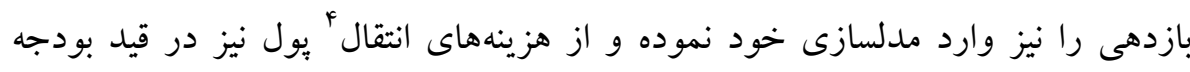

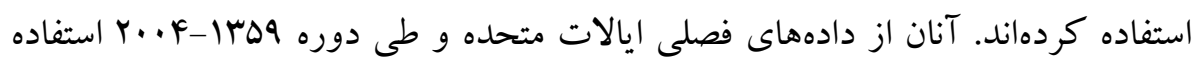

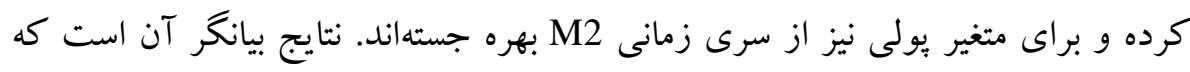

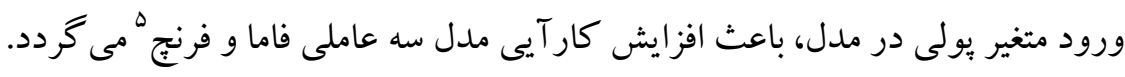

1. Gannathan and Wang

2. Zhang

3. Balvers, and Huang

4. Transaction Costs

5. Fama and French 


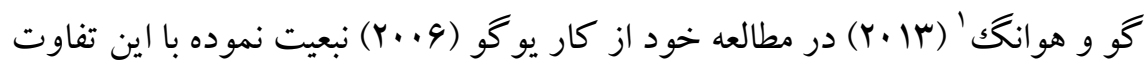
كه به جاى استفاده از مصرف كالاهاى غير بادوام در تابع مطلوبيت جدايى نايذير اروايه شده

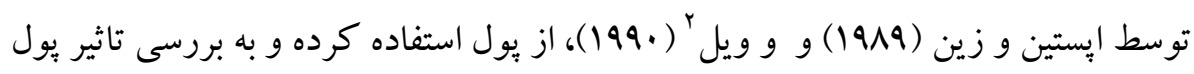

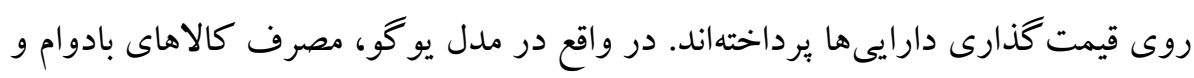

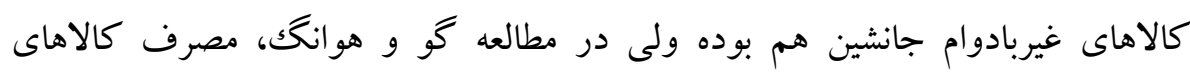

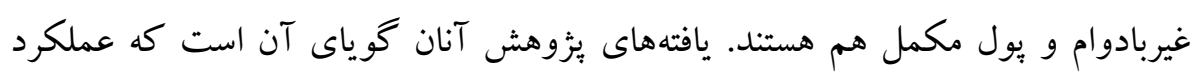

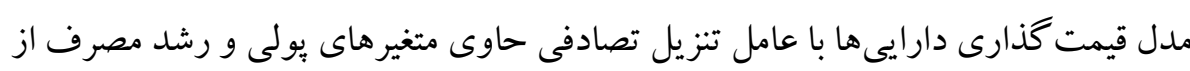

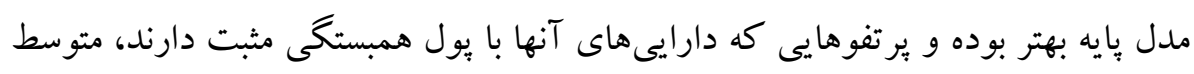

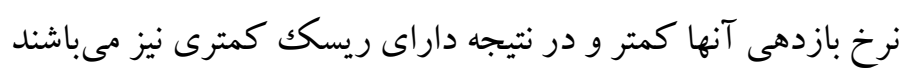

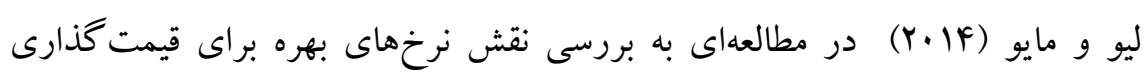

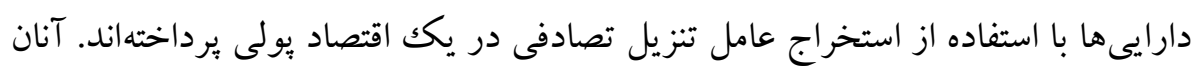

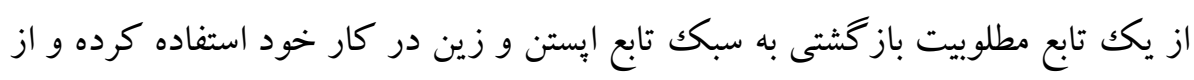

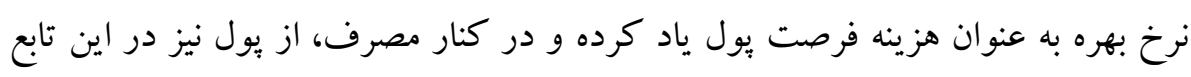

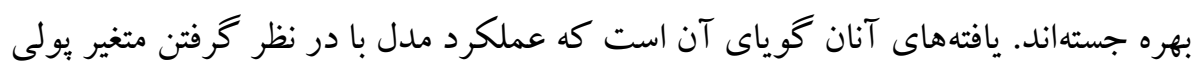

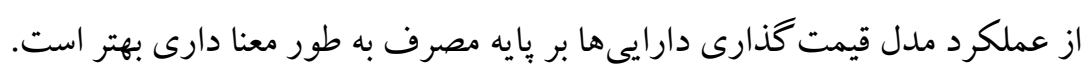

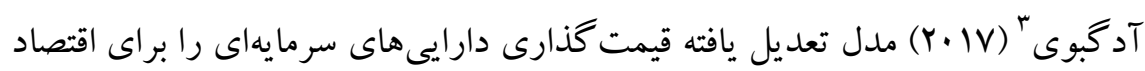

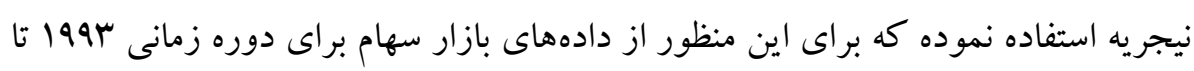

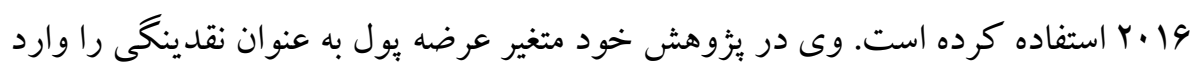

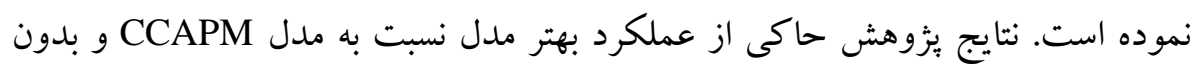
ورود متغير بولى بوده است.

1. Gu, L., and D. Huang

2. Weil

3. Adegboye Abidemi 
مير الس كويرس' و ديخران (Y.IV) به بررسى نقش نقدينكى در بازار سرمايه كشور

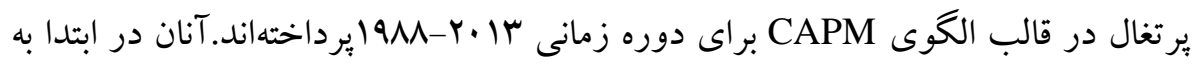

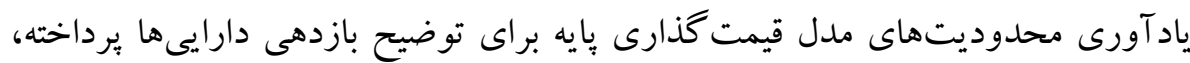

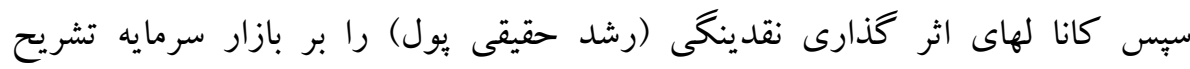

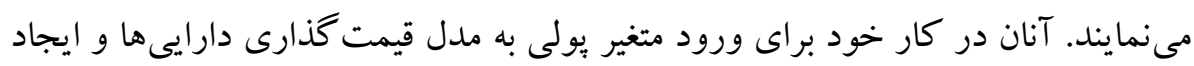

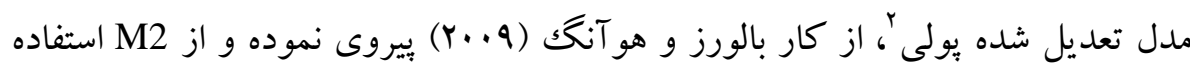

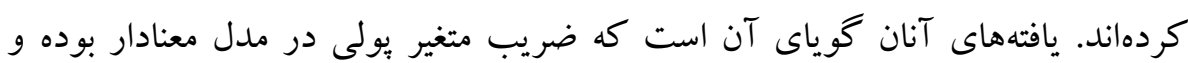

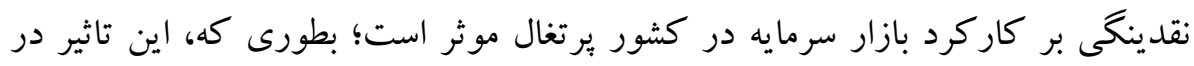

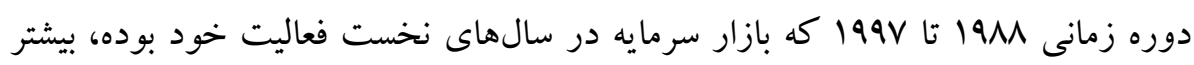
بوده است.

كميبل و همكارانَ (Y (Y) در مطالعهاى به بررسى نقش بى ثباتىها در مدلهاى

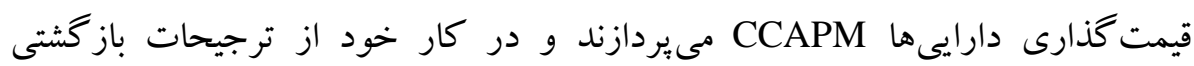

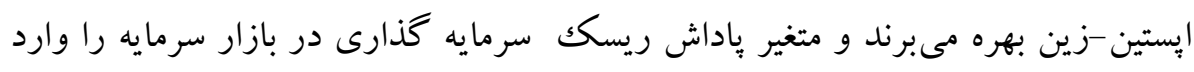

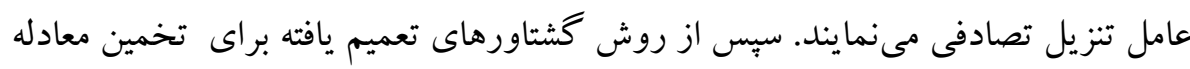

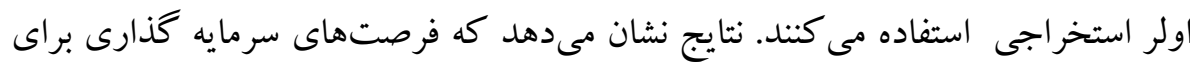
يكك سرمايه كذار به علت كاهش بازدهىهاى انتظارى يا افزايش بى ثباتى دئى در بازدهى دارايى ها، كاهش مى يابد.

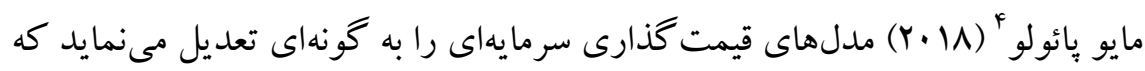

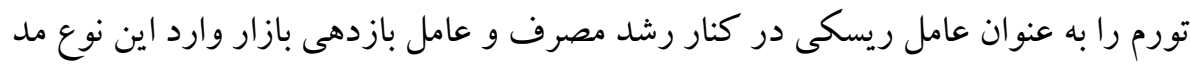

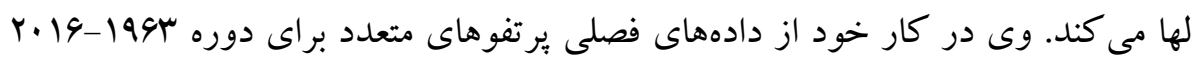
ساخته و از ترجيحات باز گشتى إيستين-زين در مدلهاى CCAPM استفاده مى كند، نتايج

1. Miralles Quiros et al.

2. Mony - Adjusted Model

3. Campbell et al.

4. Maio Paulo 
مطالعه وى بيانكر آن است كه عامل تورم نمى تواند بِاداش ريسك براى بازدهى دارايىهاى

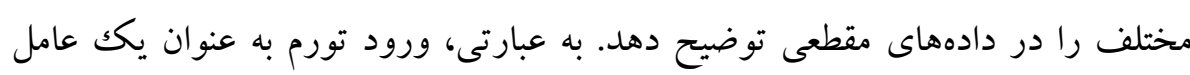

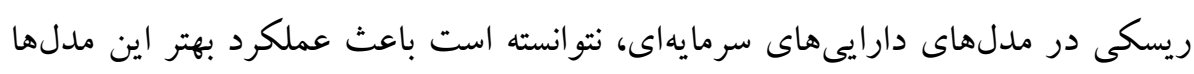
كردد.

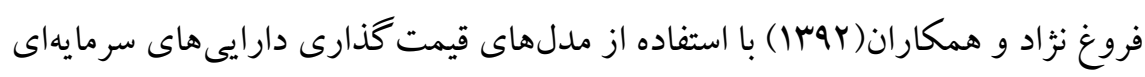

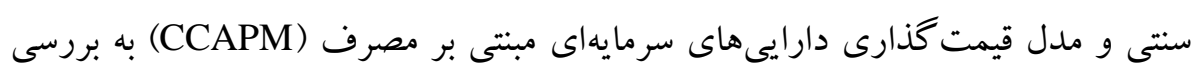

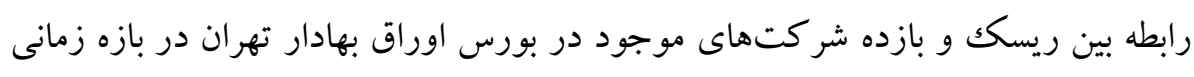

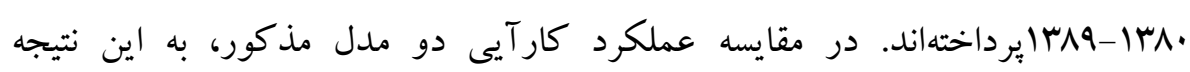
رسيدهاند كه مدل CCAPM نسبت به مدل CAPM سنتى عملكرد بهترى دارد.

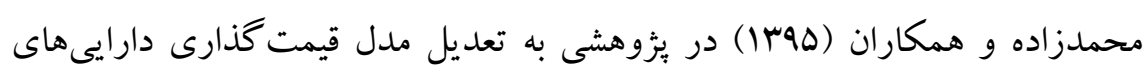

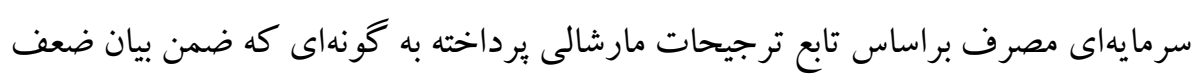

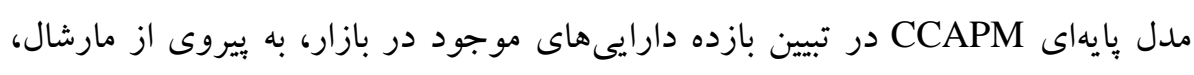

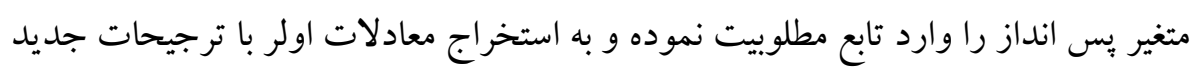

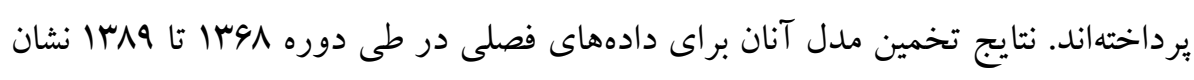

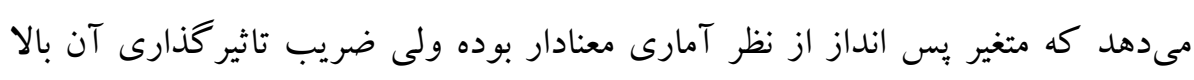
نيست. ايزدخواستى (Vqr) در مطالعهاى به تحليل تاثير سياستهاى بولى بر تورم و رفاه با

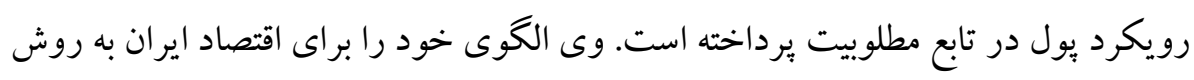

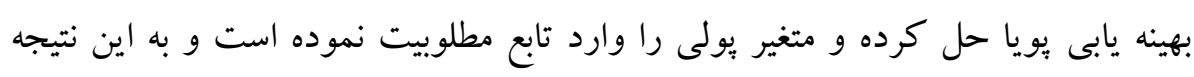

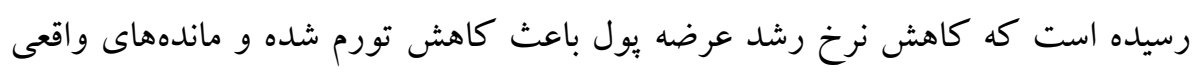

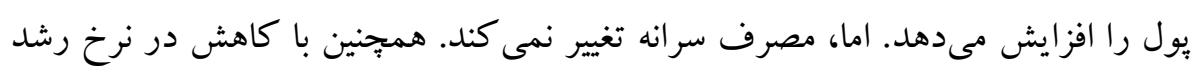

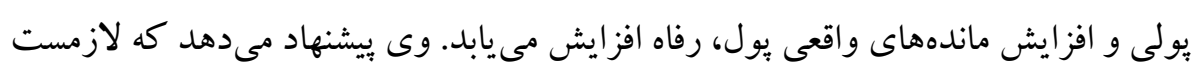

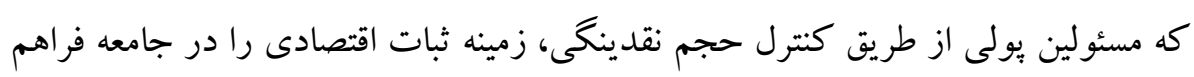




\section{r. مدل تحقيق و روش بر آورد}

در اين يزوهش سعى مىشود تا از دو نوع ترجيحات براى تعيين سهم يول در تابع

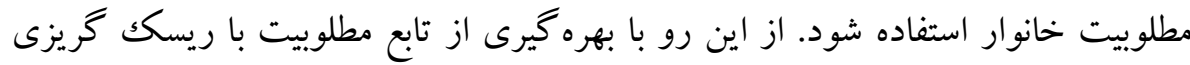

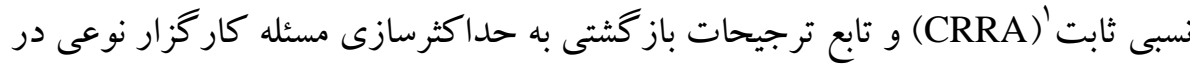
اقتصاد، در قالب مدل قيمت گذارى دارايىهاى سرمايهاى بريايه مصرف و وبول بردئ برداخته M- كه حاوى متغير تراز يولى نيزمى باشد را CCAPM مى برد، كه اين مدل تعديل يافته مىناميم. از اينرو، ابتدا نحوه ورود عامل ريسك بولى به عامل تنزيل تصادفى CCAPM

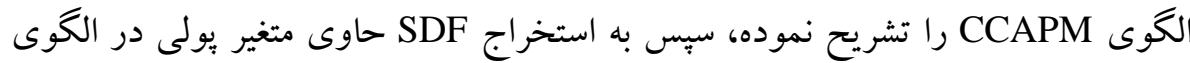
قيمت گذارى دارايى ها با لحاظ تابع ترجيحات باز گشتى مى يردازيم.

\section{r-1. استخراج SDF حاوى فاكتور ريسكى تراز يولى با بكاركيرى تابع}

\section{مطلوبيت با ريسك كريزى نسبى ثابت}

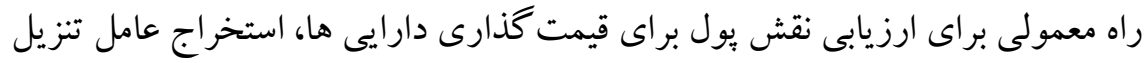

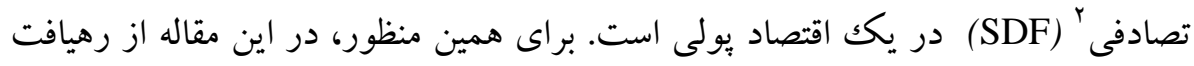

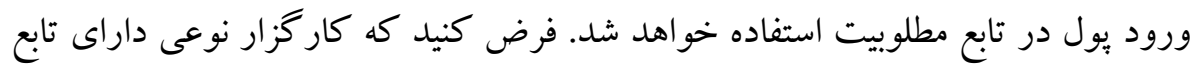

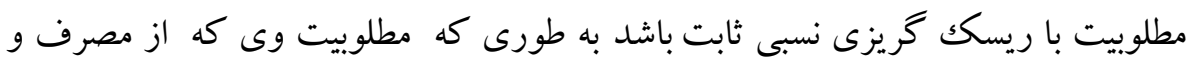
تراز واقعى يول بدست مى آيد با استفاده از تابع كاب-دا كلاس به صورت زير تعريف شود: $U\left(C_{t}, M_{t}\right)=\frac{\left(C_{t}^{1-\epsilon} M_{t}^{\epsilon}\right)^{1-\gamma}}{1-\gamma}$

كه C نشان دهنده مصرف، M بيانگر تراز واقعى يول، үضريب ريسك گريزى نسبى، و

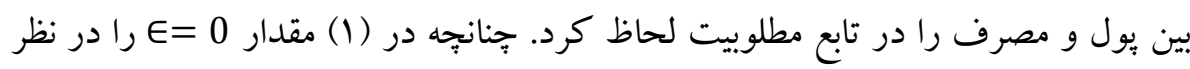

1. Constant Relative Risk Aversion

2. Stochastic Discount Factor 
بحيريم، به تابع مطلوبيت توانى استاندارد مىرسيم كه مهر او برسكات (1911) براى تشريح معماى صرف سهام از آن استفاده كردند.

ثروت مصرف كننده نوعى، تر كيبى از يول واقعى نخهدارى شده، دارايىهاى ريسكى،

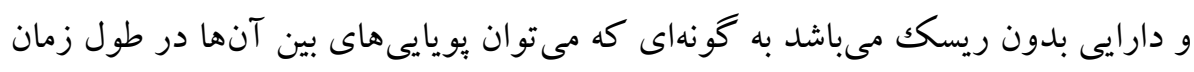
را، به صورت قيد بودجه زير نشان داد:

$W_{\mathrm{t}+1}=R_{\omega, \mathrm{t}+1}\left(W_{\mathrm{t}}-C_{\mathrm{t}}-\frac{\mathrm{R}_{\mathrm{f} \mathrm{t}+1}-1}{\mathrm{R}_{\mathrm{f}, \mathrm{t}+1}} M_{\mathrm{t}}\right)$

9

$R_{\omega, \mathrm{t}+1}=\sum_{\mathrm{i}=1}^{\mathrm{N}} \omega_{\mathrm{i}, \mathrm{t}}\left(R_{\mathrm{i}, \mathrm{t}+1}-R_{\mathrm{r}, \mathrm{t}+1}\right)+R_{\mathrm{r}, \mathrm{t}+1}$

كه $W_{\mathrm{t}+1}$ واقعى كل ثروت،

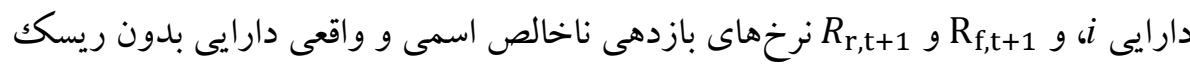

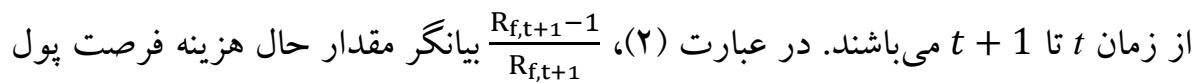
مىباشد كه در واقع همان "قيمت " يول نخهارى شده است يكى از مكانيزمهاى تبديل يول به دارايىها در اقتصاد، از طريق تاثير آن بر مطلوبيت نهايى مصرف و بنابر اين روى SDF مى باشد. از اين رو، به منظور استخراج SDF، مى متوان

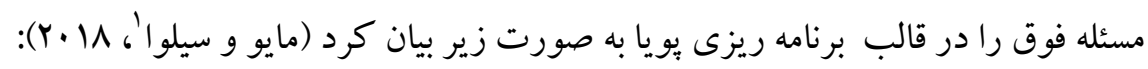

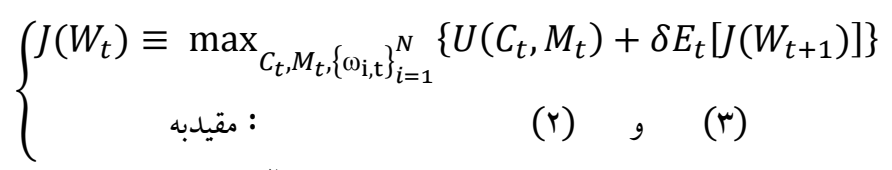

كه $\delta$ عامل تنزيل ذهنى زمانى مىباشد. شرط مرتبه اول 'نسبت به

$U_{c}\left(C_{t}, M_{t}\right)=\delta E_{t}\left[J\left(W_{t+1}\right) R_{\omega, \mathrm{t}+1}\right]$

1. Maio Paulo, Silva

2. First Order Condition (F.O.C) 
$U_{m}\left(C_{t}, M_{t}\right)=\delta E_{t}\left[J\left(W_{t+1}\right) R_{\omega, \mathrm{t}+1} \frac{\mathrm{R}_{\mathrm{f}, \mathrm{t}+1}-1}{\mathrm{R}_{\mathrm{f}, \mathrm{t}+1}}\right]$

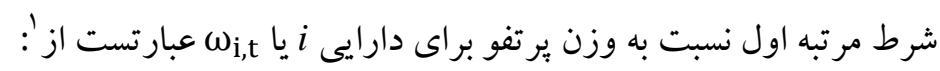

$\delta E_{t}\left[J_{W}\left(W_{t+1}\right)\left(W_{\mathrm{t}}-C_{\mathrm{t}}-\frac{\mathrm{R}_{\mathrm{f}, \mathrm{t}+1}-1}{\mathrm{R}_{\mathrm{f}, \mathrm{t}+1}} M_{\mathrm{t}}\right)\left(R_{\mathrm{i}, \mathrm{t}+1}-R_{\mathrm{r}, \mathrm{t}+1}\right)\right]=0$

با بكار گيرى تئورى بوش روى (F) و استفاده از شروط مرتبه اول (ه) تا (V) مى توان

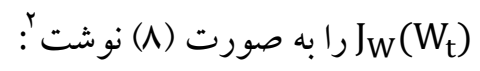

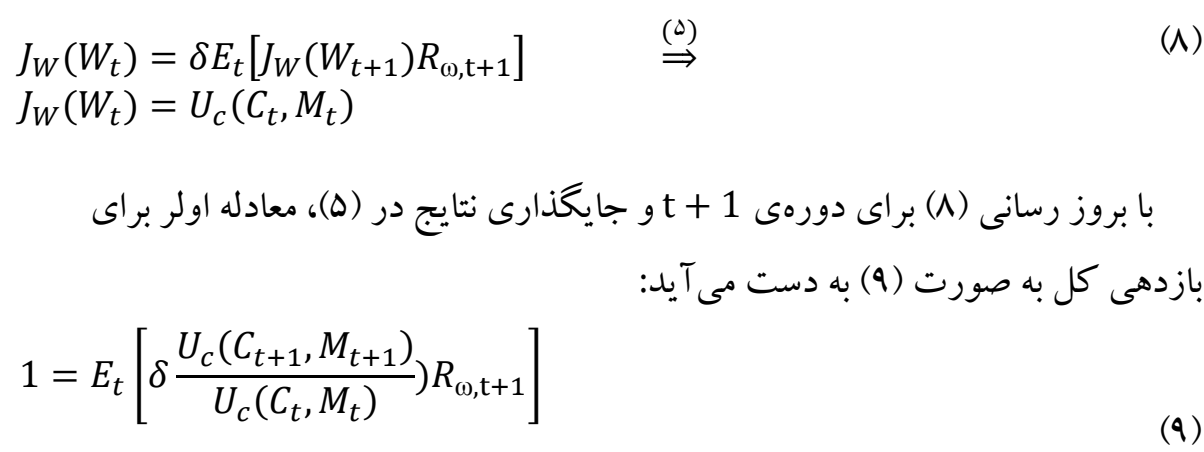

كه (9) دلالت بر اين دارد كه SDF برابر است با:

$Q_{t+1}=\frac{U_{c}\left(C_{t+1}, M_{t+1}\right)}{U_{c}\left(C_{t}, M_{t}\right)}$

با در نظر گرفتن تابع مطلوبيت مدل اول يا (1)، و رابطه ( •(1)، به عامل تنزيل تصادفى (C)

SDF به صورت (11) مىرسيم.

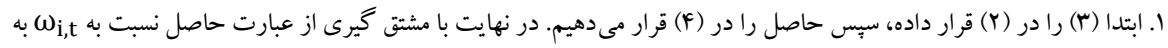

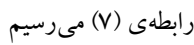

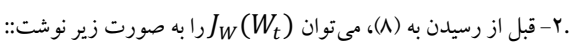
$J_{W}\left(W_{t}\right)=\frac{\partial C_{t}}{\partial W_{t}}\left\{U_{c}\left(C_{t}, M_{t}\right)-\delta E_{t}\left[J_{W}\left(W_{t+1}\right) R_{\omega, t+1}\right]\right\}+\frac{\partial M_{t}}{\partial W_{t}}\left\{U_{m}\left(C_{t}, M_{t}\right)-\right.$ $\left.\delta E_{t}\left[J_{W}\left(W_{t+1}\right) R_{\omega, \mathrm{t} t+1} \frac{\mathrm{R}_{\mathrm{f}, \mathrm{t}+1}-1}{\mathrm{R}_{\mathrm{f}, \mathrm{t}+1}}\right]\right\}+\delta E_{t}\left[J_{W}\left(W_{t+1}\right)\left(W_{\mathrm{t}}-C_{\mathrm{t}}-\frac{\mathrm{R}_{\mathrm{f}, t+1}-1}{\mathrm{R}_{\mathrm{f}, \mathrm{t}+1}} M_{\mathrm{t}}\right)\left(R_{\mathrm{i}, \mathrm{t}+1}-R_{\mathrm{r}, \mathrm{t}+1}\right)\right] \frac{\partial \omega_{i t}}{\partial W_{t}}$
} 
$Q_{t+1}=\delta\left(\frac{C_{t+1}}{C_{t}}\right)^{(1-\epsilon)(1-\gamma)-1}\left(\frac{M_{t+1}}{M_{t}}\right)^{\epsilon(1-\gamma)}$

بنابراين، عامل تنزيل تصادفى در مدل يولى با استفاده از رشد واقعى مصرف و رشد

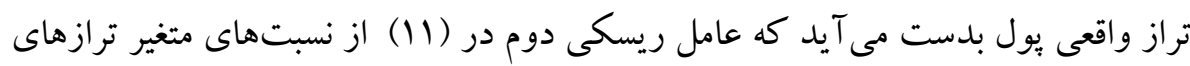
يولى در دورههاى 1 t t t t بدست مى آيد كه از حسابهاى ملى قابل اخذ است. از اين

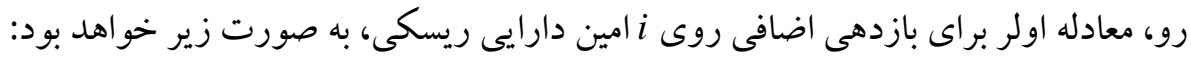
$E_{t}\left[\delta\left(\frac{C_{t+1}}{C_{t}}\right)^{(1-\epsilon)(1-\gamma)-1}\left(\frac{M_{t+1}}{M_{t}}\right)^{\epsilon(1-\gamma)} R_{i, t+1}^{e}\right]=1$

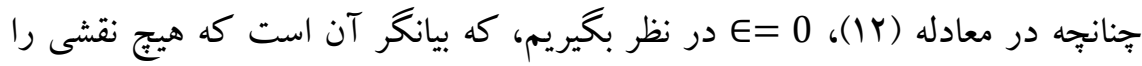
براى ترازهاى واقعى يول در تابع مطلوبيت در نظر نخيريم، به مدل استاندارد تعريف شده

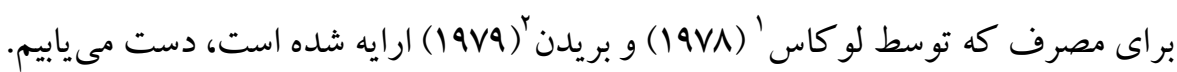
$E_{t}\left[\delta\left(\frac{C_{t+1}}{C_{t}}\right)^{-\gamma} R_{i, t+1}^{e}\right]=1$

كه معادله (rا ) را مدل مرجع در بر ابر مدل بولى مىناميم.

r-r. استخراج SDF حاوى فاكتور ريسكى تراز يولى با بكار كيرى تابع مطلوبيت باز تشتى

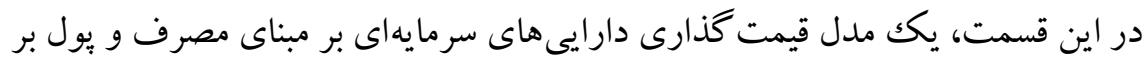

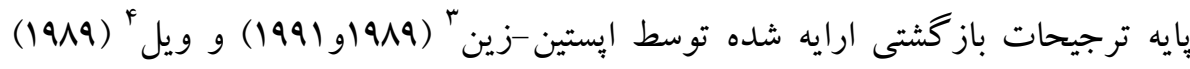
معرفى مى گردد به طورى كه در تابع مطلوبيت آن در كنار مصرف، از تراز بولى نيز استفاده مىشود. در اين مطالعه اين مدل را مدل دوم مىناميم. مىتوان تابع مطلوبيت

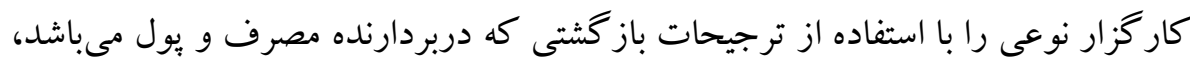

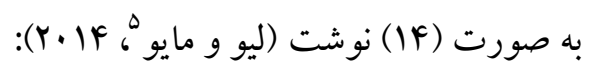

1. Lucas

2. Breeden

3. Epstein and Zin

4. Weil

5 - Lioui and Maio 
$U_{t}=\left\{(1-\delta)\left(C_{t}^{1-\epsilon} M_{t}^{\epsilon}\right)^{\frac{1-\gamma}{\theta}}+\delta\left[E_{t}\left(U_{t+1}^{1-\gamma}\right)\right]^{\frac{1}{\theta}}\right\}^{\frac{\theta}{1-\gamma}}$

كه در آن $\theta$ يكك بارامتر كمكى است كه به صورت

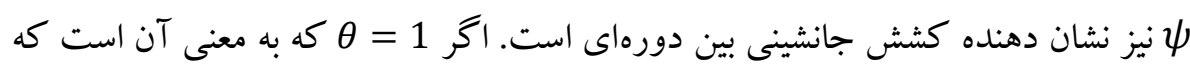
يارامتر ريسك كريزى نسبى معكوس كشش جانشينى است استفاده شده در مدل اول خو اهيم رسيد كه حالت خاصى از مدل دوم است.

به منظور استخراج SDF براى اين مدل كه در آن از ترجيحات باز گشتى و متغيرهاى

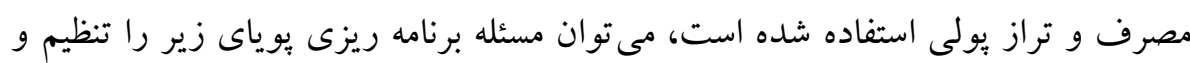

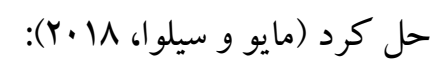

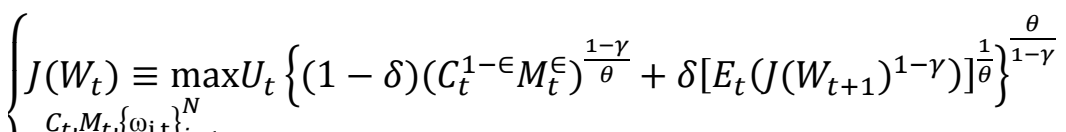
$C_{t}, M_{t},\left\{\omega_{\mathrm{i}, \mathrm{t}}\right\}_{i=1}^{N}$

(r) $\quad 9$ : مقيدبه :

$$
\text { شرط مرتبه اول' (F.O.C) نسبت به }
$$

$(1-\epsilon) C_{t}^{\frac{1-\gamma}{\theta}(1-\epsilon)-1} M_{t}^{\epsilon \frac{1-\gamma}{\theta}}$

$=\frac{\delta}{1-\delta}\left[E_{t}\left(J\left(W_{t+1}\right)^{1-\gamma}\right)\right]^{\frac{1}{\theta}-1} E_{t}\left[J\left(W_{t+1}\right)^{-\gamma} J_{W}\left(W_{t+1}\right) R_{\omega, \mathrm{t}+1}\right]$

$\in C_{t}^{\frac{1-\gamma}{\theta}(1-\epsilon)} M_{t}^{\in \frac{1-\gamma}{\theta}-1} \frac{\mathrm{R}_{\mathrm{f}, \mathrm{t}+1}}{\mathrm{R}_{\mathrm{f}, \mathrm{t}+1}-1}$

$=\frac{\delta}{1-\delta}\left[E_{t}\left(J\left(W_{t+1}\right)^{1-\gamma}\right)\right]^{\frac{1}{\theta}-1} E_{t}\left[J\left(W_{t+1}\right)^{-\gamma} J_{W}\left(W_{t+1}\right) R_{\omega, \mathrm{t}+1}\right]$

همانند إيتين و زين (1991)، فرض مى كنيم كه تابع مقدار را بتوان به صورت نسبتى از

ثروت نوشت. يعنى

$$
\text { انتظارات تكر ارى و قيد بودجه (Y)، خو اهيم داشت: }
$$

1 -First Order Condition 


$$
\begin{aligned}
& C_{t}^{\frac{1-\gamma}{\theta}(1-\epsilon)-1} M_{t}^{\epsilon \frac{1-\gamma}{\theta}} \\
& =\frac{\delta}{1-\delta} \frac{1}{1-\epsilon}\left[E_{t}\left(J\left(W_{t+1}\right)^{1-\gamma}\right)\right]^{\frac{1}{\theta}}\left(W_{\mathrm{t}}-C_{\mathrm{t}}\right. \\
& \left.-\frac{\mathrm{R}_{\mathrm{f}, \mathrm{t}+1}-1}{\mathrm{R}_{\mathrm{f}, \mathrm{t}+1}} M_{\mathrm{t}}\right)^{-1} \\
& \text { بعلاوه، تابع مقدار در (ها) را مىتوان به صورت زير نوشت: } \\
& J\left(W_{t}\right)^{\frac{1-\gamma}{\theta}}-(1-\delta)\left(C_{t}^{1-\epsilon} M_{t}^{\epsilon}\right)^{\frac{1-\gamma}{\theta}}=\delta\left[E_{t}\left(J\left(W_{t+1}\right)^{1-\gamma}\right)\right]^{\frac{1}{\theta}} \\
& \text { با جايگذارى (19) در (1) و بعد از تعدادى عمليات جبرى ساده، شكل تابعى براى } \\
& \text { تابع مقدار به صورت زير بدست مى آيد': } \\
& J(W)=(1-\delta)^{\frac{\theta}{1-\gamma}}(1-\epsilon)^{\frac{\theta}{1-\gamma}}\left(\frac{C_{\mathrm{t}}}{W_{\mathrm{t}}}\right)^{1-\frac{\theta}{1-\gamma}}\left(\frac{M_{\mathrm{t}}}{C_{\mathrm{t}}}\right)^{\epsilon} W_{\mathrm{t}}=\emptyset_{t} W_{t}
\end{aligned}
$$

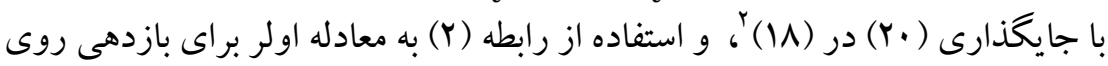

$$
\begin{aligned}
& \text { ير تفوى بازار به صورت ( إl) مىرسيم: } \\
& E_{t}\left[\delta^{\theta}\left(\frac{C_{t+1}}{C_{t}}\right)^{(1-\epsilon)(1-\gamma)-\theta}\left(\frac{M_{t+1}}{M_{t}}\right)^{\epsilon(1-\gamma)} R_{\omega, \mathrm{t}+1}^{\theta}\right]=1 \\
& \text { مى توان شكل كلى معادله اولر متناظر با (Y) را به صورت (Yr) نوشت: } \\
& E_{t}\left[Q_{t+1} R_{i, t+1}^{e}\right]=0 \\
& \text { كه عامل تنزيل تصلدفى SDF مربوط به معادله (YY) به شكل (YY) خواهد بود: } \\
& Q_{t+1}=\delta^{\theta}\left(\frac{C_{t+1}}{C_{t}}\right)^{(1-\epsilon)(1-\gamma)-\theta}\left(\frac{M_{t+1}}{M_{t}}\right)^{\epsilon(1-\gamma)} R_{\omega, \mathrm{t}+1}^{\theta-1} \\
& \text { عامل تنزيل تصادفى مدل دوم يا رابطه (Tr)، نسبت به عامل تنزيل مدل اول يا رابطه } \\
& \text { (11)، يكك عامل ريسكى اضافى نيز دارد كه }
\end{aligned}
$$

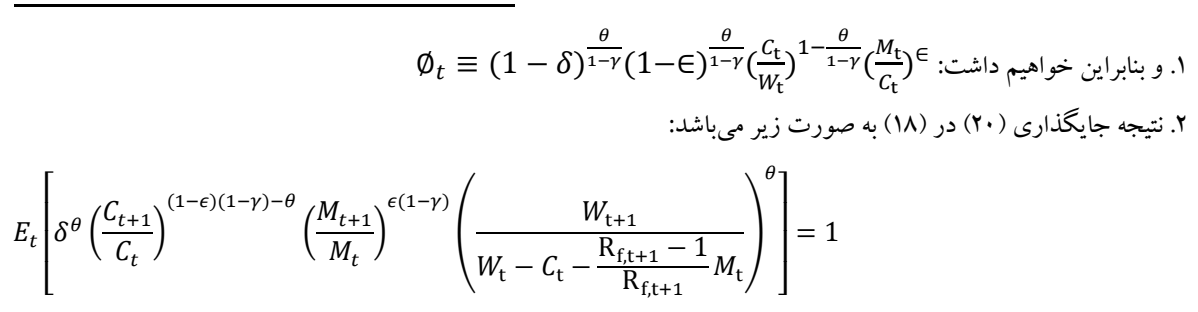


است. اخر E=0 (يعنى هيج نقشى را براى يول در تابع مطلوبيت در نظر نخيريم)، كرنل

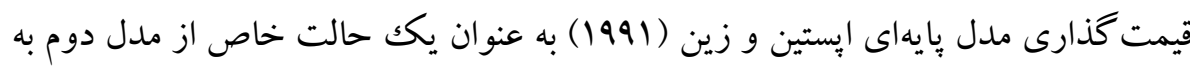
$Q_{t+1}=\delta^{\theta}\left(\frac{C_{t+1}}{C_{t}}\right)^{(1-\gamma)-\theta} R_{\omega, \mathrm{t}+1}^{\theta-1}$ صورت زير حاصل خواهد شد:

\section{r-r"r. معيارهاى انتخاب مدل برتر در بين مدل هاى رقيب}

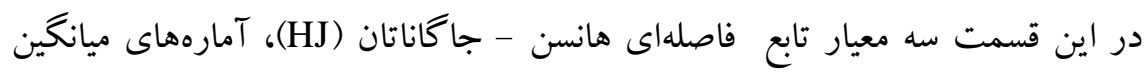
قدرمطلق خطاها و ميانگين مجموع مجذور خطاها كه در بخش تجربى از آنها براى تعيين مدل برتر استفاده مىشود، معرفى مى گردند.

\section{ץ-ץ-1. تابع فاصلهاى هانسن - جاكاناتان (HJ)}

فرض كنيد كه Q همان عامل تنزيل تصادفى (SDF) الكوى مورد نظر بوده و R

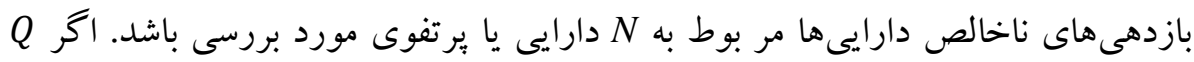
قيمتهاى صحيح N يرتفوى مورد نظر باشد و به عبارتى مدل به طور كامل و صحيح

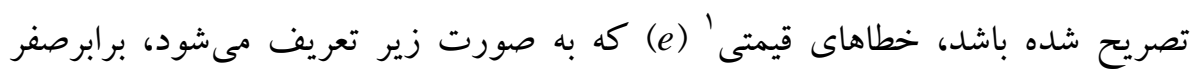
$\mathrm{e} \equiv E[R Q]-\mathbf{1}_{N} \equiv \mathbf{0}_{N}$

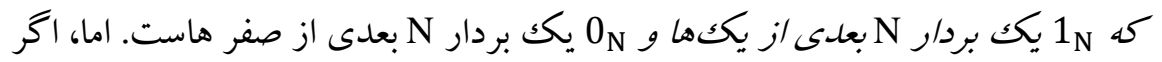

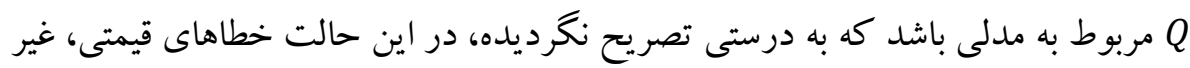
صفر خواهند بود. در اغلب حالات، عامل تنزيل تصادفى (Q) حاوى تعدادى پيارامتر

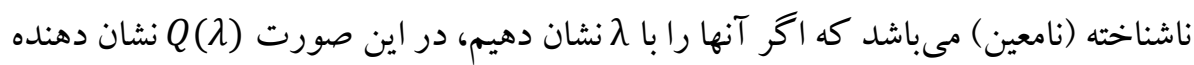
عامل تنزيل تصادفى مدلى است كه به درستى تصريح نشده و در اين صورت خواهيم 
$\mathrm{e}(\lambda)=E[R Q(\lambda)]-\mathbf{1}_{N} \neq \mathbf{0}_{N}$

هر كاه يكك مدل قيمت گذارى دارايى به درستى تصريح نشده باشد، محققان علاقمندند

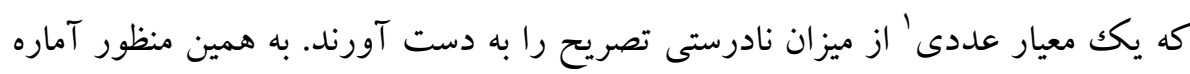

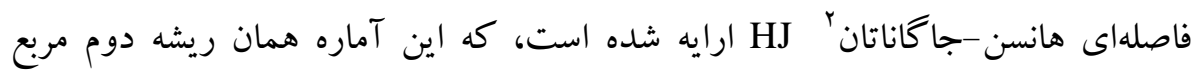
خطاهاى قيمت گذارى بوده كه به شكل زير تعريف مى هاس هود:

$\delta=\left[\mathrm{e}(\lambda)^{\prime} \mathrm{W}_{\mathrm{HJ}} \mathrm{e}(\lambda)\right]^{\frac{1}{2}}$

ماتريس گثناور دوم بازدهى دارايىها و $\mathrm{W}_{\mathrm{HJ}}=\left(\frac{1}{T} \sum_{i=1}^{T} R_{t}^{e} R_{t}^{R^{\prime \prime}}\right)^{-1}$ دهنده بردار بازدهى دارايىها در زمان t يا برتفوهاست. WH بيانكر آن است كه دارايى

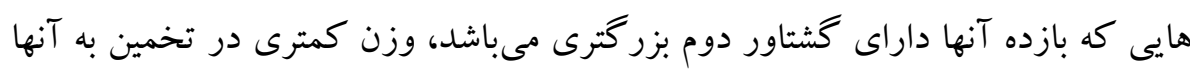

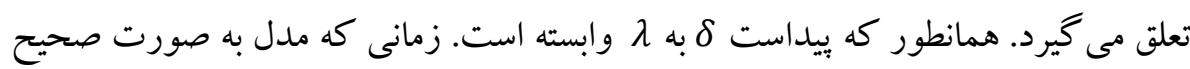
تصريح نشده باشد، مرسوم است كه لحى انتخاب شود كه آماره HJ را حداقل نمايد. تحت

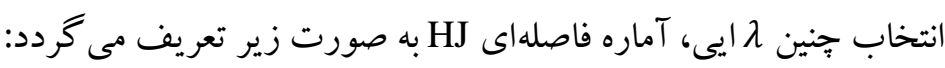

$H J=\left[\min _{\lambda} \mathrm{e}(\lambda)^{\prime} \mathrm{W}_{\mathrm{HJ}} \mathrm{e}(\lambda)\right]^{\frac{1}{2}}$

در واقع e( e بردار خطاهاى معادله اولر بوده و HJ بيانخر حداقل فاصله بين عامل

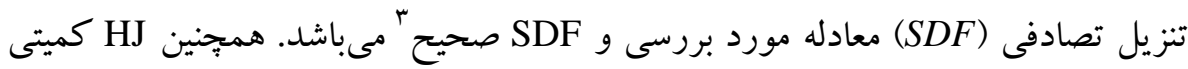

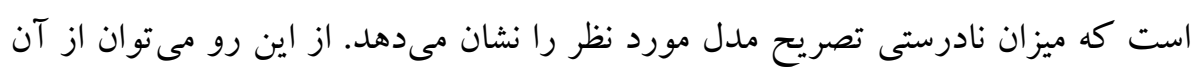

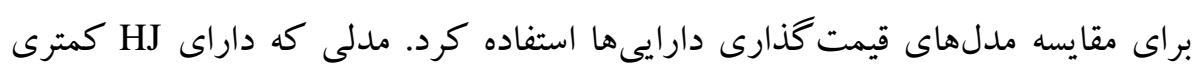

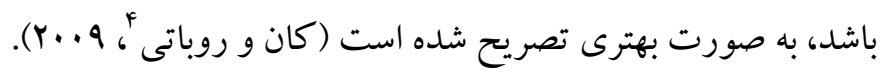

1. Scalar Measure

2. Hansen-Jagannathan

3. true SDF

4. Kan \& Robotti 
r-r-r-r. T آمارههاى ميانغين قدرمطلق خطاها و ميانغين مجموع مجذور خطاها

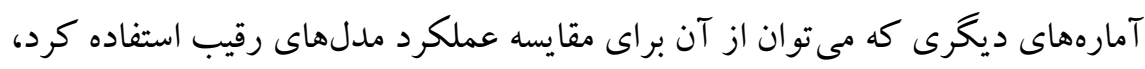
ميانگين قدرمطلق خطاها و ميانگين مجموع مجذور خطاهاست كه به صورت زير تعريف MAE $=\frac{1}{T} \sum_{i=1}^{T}\left|e_{i, T}(b)\right|$ $M S E=\frac{1}{T} \sum_{i=1}^{T}\left[e_{i, T}(b]^{2}\right.$ كه در آن $e_{i, T}$ نشان دهنده خطاى مربوط به i امين شرط گشتاورى در تخمين به روش

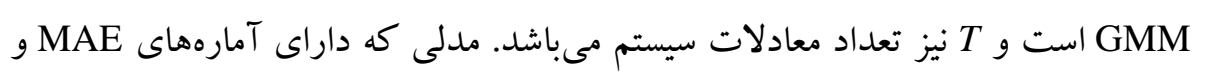
كمترى باشد، داراى عملكرد بهترى خو اهد بود.

\section{†. بروسى تجربى و يافته هاى بذوهش}

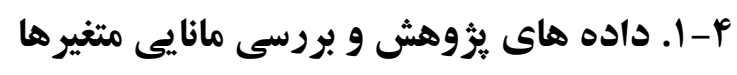

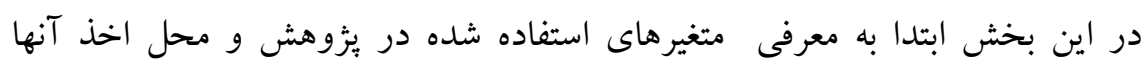

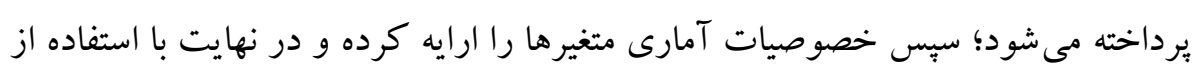

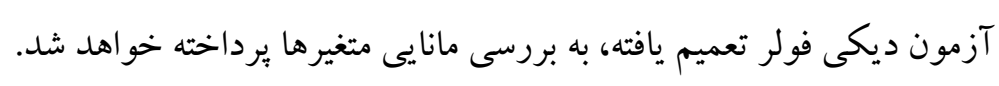

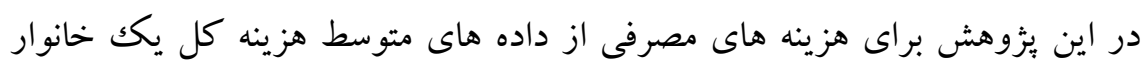

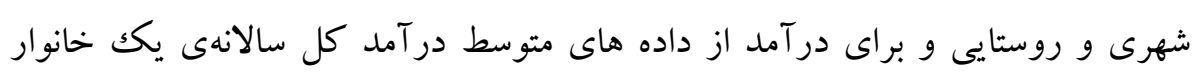

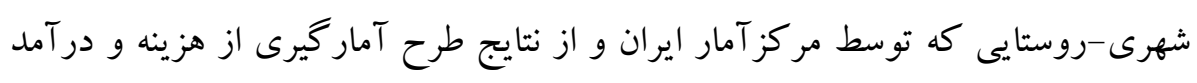

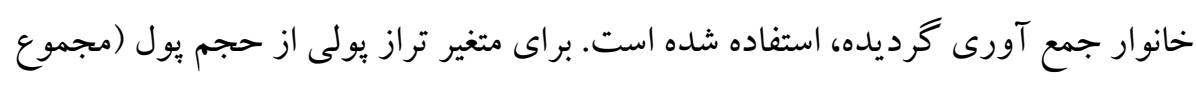

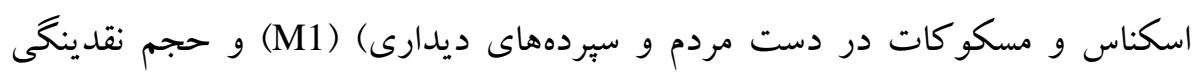

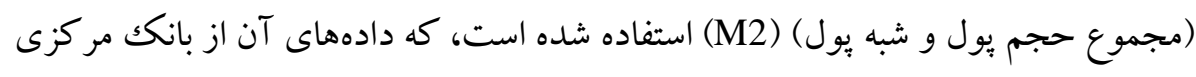

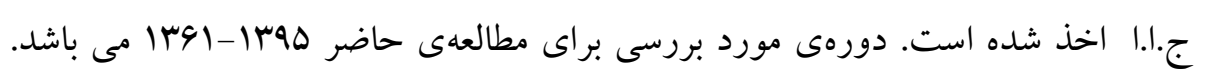


داده هاى مذكور با استفاده از شاخص قيمت مصرف كننده سال . qسا واقعى شدهاند. داده

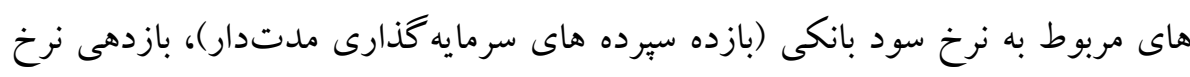

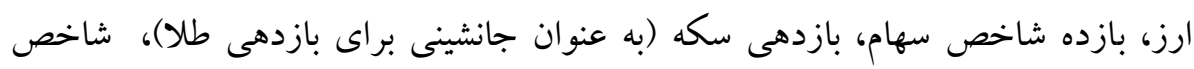

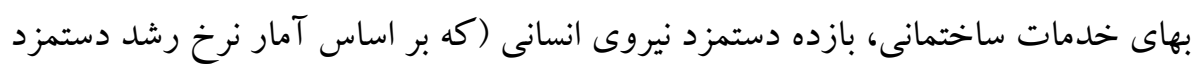

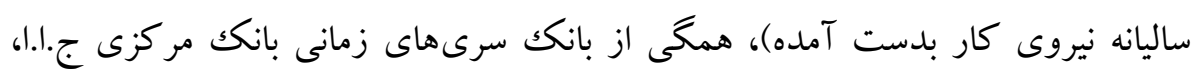

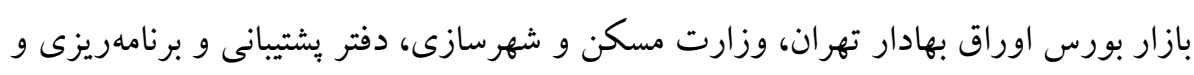

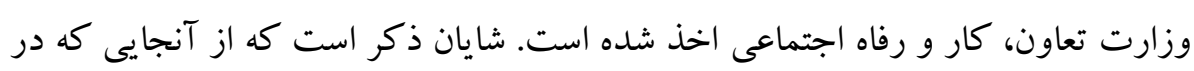

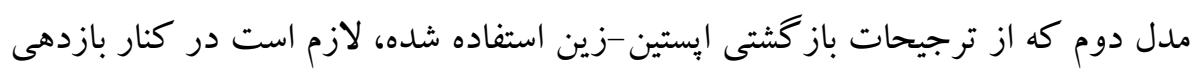

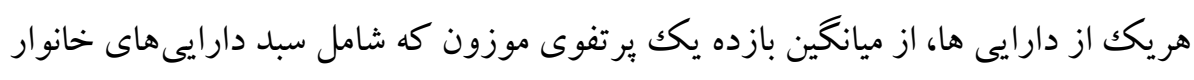

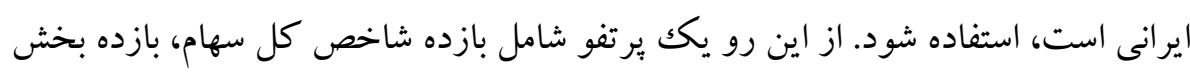

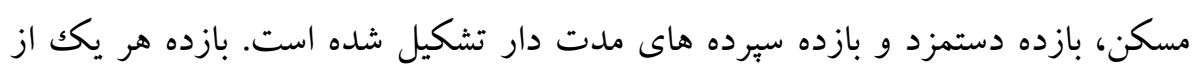

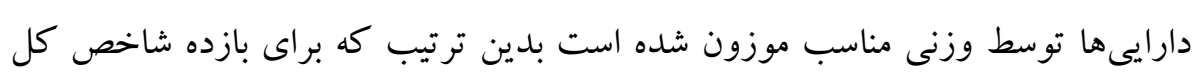

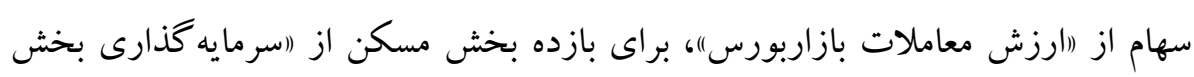

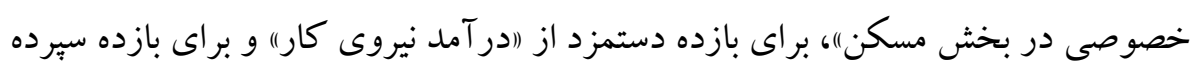

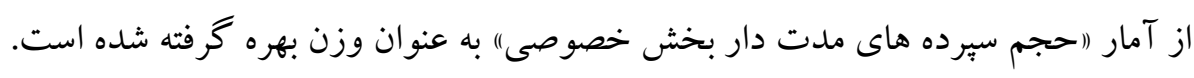

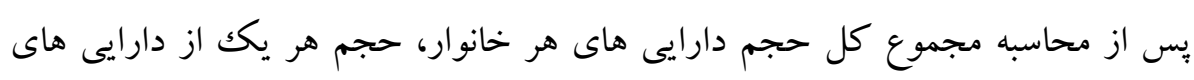

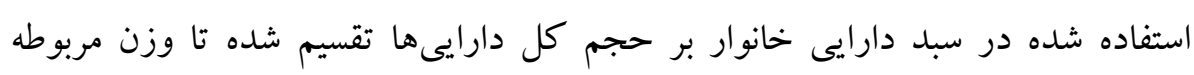
حاصل شود و در نهايت براى محاسبه ى متوسط بازدهى برتفوى خانو ار، هر يكك از وزنها

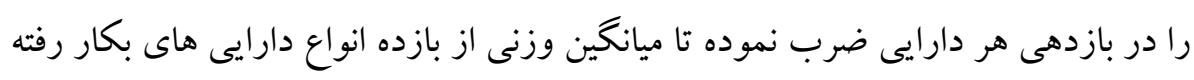
در سبد مذكور بدست آيد و از آن در معادلهى (YI) به جاى

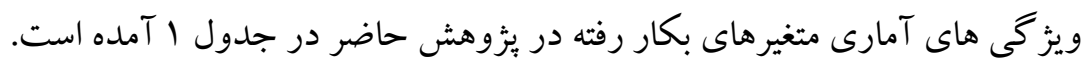




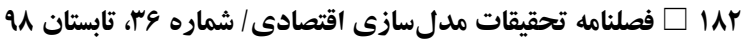

جدول 1. خصوصيات آمارى متغيرهاى استفاده شده در ثزوهش

\begin{tabular}{|c|c|c|c|c|c|c|c|c|c|}
\hline ثرِ ثرتفوى & بازده سهام & هاز بانكي سيرده & 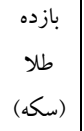 & مسكن & بازده نرخ & نقديت سلخى دو & نسبت حجم يول دو سال & سبت مصرف دو متوالى & آمارى \\
\hline PORTFO & SAHAM & RATE & COIN & HOUS & EXH & $\frac{M_{2 t+1}}{M_{2 t}}=\mathrm{M} 2 \mathrm{M} 0$ & $\frac{M_{1 t+1}}{M_{1 t}}=\mathrm{M} 1 \mathrm{M} 0$ & $1 \cdot \frac{C_{t+1}}{C_{t}}=\mathrm{CONS}$ & علامت \\
\hline.$/ 194$ & . &.$/ A K$ & $\cdot / r r$. & $\cdot / r / Y$ & . & $1 / .49$ & $1 / .19$ & $1 / . \mu F$ & ميانگين \\
\hline$\cdot / \cdot \lambda F$ & - $/ F F \Delta$ &.$/ . \mathrm{rq}$ & - /YDG &.$/ .94$ & - MrG & $\cdot / \cdot \lambda F$ & .1 .99 & $\cdot / \cdot V^{F}$ & انحر اف معيار \\
\hline • & I/YFA & r & - IAFY & • & . $/ 94$ & $1 / r \Delta$ & $1 / I V$ & $1 / 19$ & ماكزيمم \\
\hline.$/ \cdot r \Delta$ & $-\cdot / Y 19$ & .11 & $-\cdot / \cdot 1$ & $\cdot / \cdot \wedge V$ & -.1 .9 & . $/ 94$ & $\cdot / \mathrm{VA}$ & $\cdot|A|$ & مينيمم \\
\hline ./1rq & - /TOG &.$/ l f$. & $\cdot / \mid \mathrm{VI}$ & $\cdot / 1 \wedge \Delta$ &.$/ \cdot \Delta$ & $1 / .+1$ & $1 / \cdots 9$ & $1 / \cdot F$ & ميانه \\
\hline • & $\cdot / A \cdot 1$ & $1 /$ TFG & $\cdot / 9 \Delta \mathrm{V}$ & - $/$ FA & $1 / 199$ & סחז/. & -101 & $-\cdot / V \Delta$ & جولخى \\
\hline l/A9r & $r / 901$ & F/VIr & سזוא & I/arr & $9 / 49$. & T/MY & $r / 9 V$ & $r / \Delta F$ & كشيدگى \\
\hline
\end{tabular}

منبع: يافتهاى بثزوهش

از آنجايى كه در اين مقاله از روش گُشتاورهاى تعميم يافته براى برآورد يُارامترهاى معادلات اولر استخراج شده، استفاده مىشود، لازمست كه مانايى متغيرهاى مورد استفاده

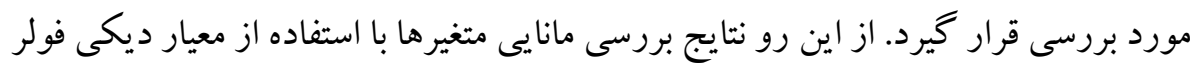
تعميم يافته در جدول (Y) ارايه شده است.

جدول r. نتايج بررسى مانايى متغيرهاى استفاده شده در يخوهش

\begin{tabular}{|c|c|c|c|c|}
\hline $\begin{array}{c}\text { مقداربحر انى } \\
\text { ADF }\end{array}$ & $\begin{array}{c}\text { آماره آزمون } \\
\text { ADF }\end{array}$ & وضعيت & 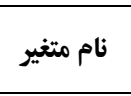 & متغير \\
\hline$-Y / Q Y$ & $-F / V \Delta$ & با عرض از مبداً & $1 \cdot \mathrm{CONS}$ & نسبت مصرف در دو سال متوالى \\
\hline$-r / 9 F$ & $-0 / \cdot 9$ & با عرض از مبداً & M1M0 & نسبت حجم يول در دو سال متوالى \\
\hline$-Y / Q F$ & $-\varphi / \mu q$ & با عرض از مبداً & M2M0 & نسبت حجم نقدينگى در دو سال متوالى \\
\hline$-r / 9 F$ & $-F / l f$ & با عرض از مبداً & EXH & بازده نرخ ارز \\
\hline$-r / 9 F$ & $-r / I r$ & با عرض از مبداً & HOUS & بازده مسكن \\
\hline$-r / 9 F$ & $-\Delta / a r$ & با عرض از مبداً & COIN & بازده طلا (سكه) \\
\hline$-r / \Delta 9$ & $-r / 99$ & با عرض از مبداً و روند & RATE & بازده سيرده هاى بانكى \\
\hline$-r / 99$ & $-r / \mu r$ & با عرض از مبداً & SAHAM & بازده سهام \\
\hline$-Y / 9 F$ & $-r / \cdot V$ & با عرض از مبداً & PORTFO & ير تفوى ثروت \\
\hline
\end{tabular}


همانطور كه نتايج جدول (Y) نشان مى دهد كليهى متغيرهاى يزوهش در سطح معنادارى ها مانا مى باشند؛ به طورى كه آزمون ديكى -فولر تعميم يافته مانايى متغيرها را تاييد مى منمايد.

† F-r. برآورد معادلات اولر و تخمين ضريب سهم تراز يولى در تابع مطلوبيت

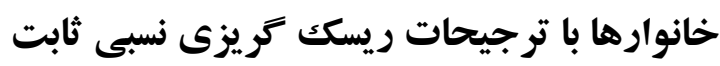

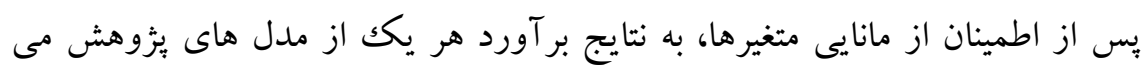

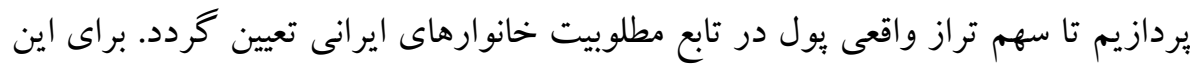

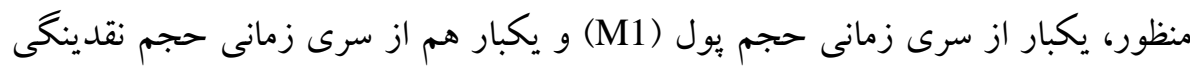
بجاى متغير تراز واقعى يول در مدلهاى مطرح شده در يزوهش، استفاده مىنماييم.

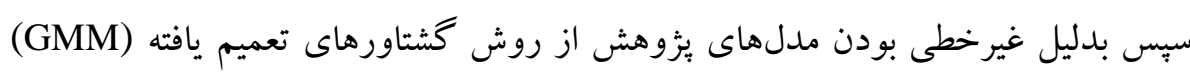

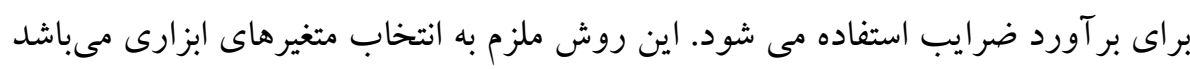

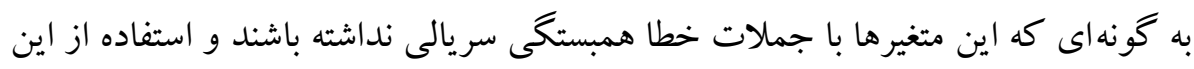

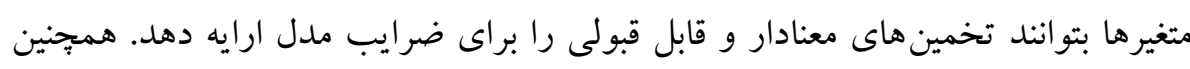
لازم به توضيح است كه از آنجايى كه براى تخمين ضرايب، روش GMM از از الكوريتم

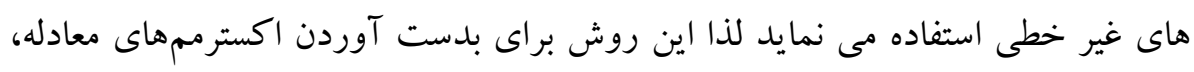

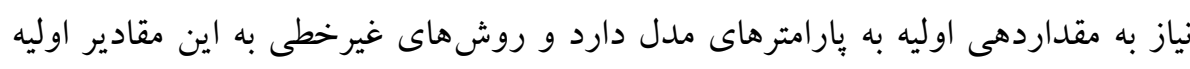

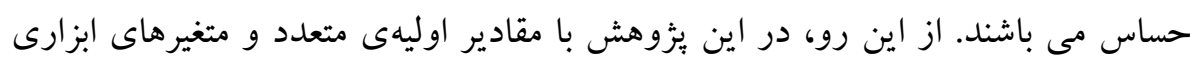
مختلف كه عموماً وقفه هاى متغيرهاى بكاررقته در مدل به همراه عرض ازئ از مبدأ مى بـاشد، استفاده شده است. يس از تخمينهاى متعدد به روش GMM و با استفاده از مقادير اوليه و متغيرهاى

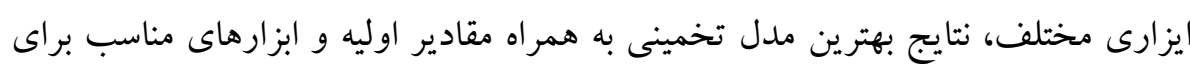

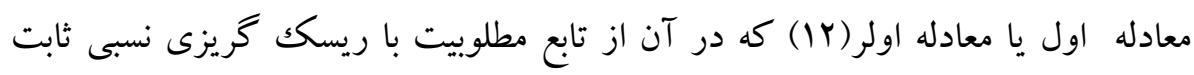
استفاده شده و شامل مصرف و حجم بول (M1) است، در جدول (r) ارايه مى كردد. 


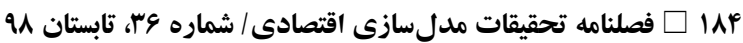

جدول r. نتايج تخمين مدل اول با وجود حجم يول (M1) از روش GMM

\begin{tabular}{|c|c|c|c|c|c|c|}
\hline بحرانى J آل & آماره J & نرم آفزار خروجى & $\gamma$ & $\epsilon$ & $\boldsymbol{\delta}$ & $\begin{array}{c}\text { مقادير اوليه } \\
(\boldsymbol{\gamma}, \boldsymbol{\epsilon}, \boldsymbol{\delta})\end{array}$ \\
\hline$r V / \Delta \Lambda$ & $9 /, / 1$ & $\cdot / 499$ & $\begin{array}{c}r N / Y \\
"(19 / N G)\end{array}$ & 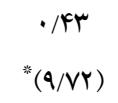 & $\begin{array}{l}\cdot / V \Lambda \\
\cdot(1 / / \Delta r)\end{array}$ & $\left(\cdot / \cdot \sigma / / \Gamma_{6} / / \Delta\right)$ \\
\hline \multicolumn{7}{|c|}{ آزمونهاى تشخيصى } \\
\hline \multicolumn{3}{|c|}{ مقداراحتمال(P_value) } & \multicolumn{3}{|c|}{ مقدار آماره } & آزمون \\
\hline \multicolumn{3}{|c|}{$\cdot / \Delta V$} & \multicolumn{3}{|c|}{$\| F / N V$} & خودهمبستخى \\
\hline \multicolumn{3}{|c|}{$\cdot|r|$} & \multicolumn{3}{|c|}{$1 / v$} & كاهمسانى واريانس \\
\hline
\end{tabular}

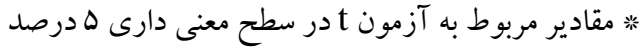

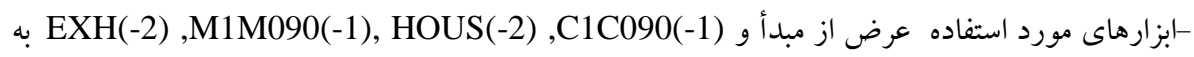

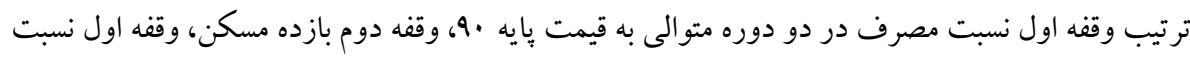
حجم يول در دو سال متوالى به قيمت بايه •9، و وقفه دوم بازده نرخ ارزمى باشند.

ساز گارى تخمين زننده GMM به معتبر بودن فرض عدم همبستگى سريالى جملات

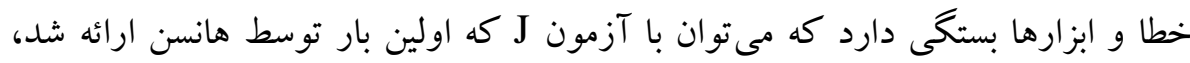

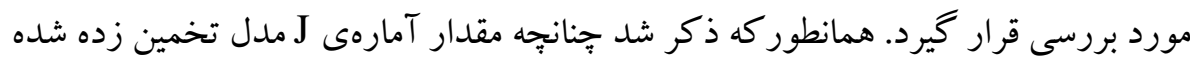
(خروجى نرم افزار ايويوز) در تعداد مشاهدات ضرب گرددد، مقدار حاصل داراى توزيع كاى-دو مىشود، به طورى كه درجه آزادى توزيع كاى-دوى حاصل، از حاصلضرب

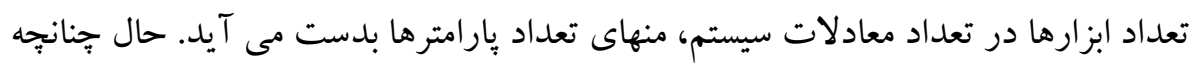

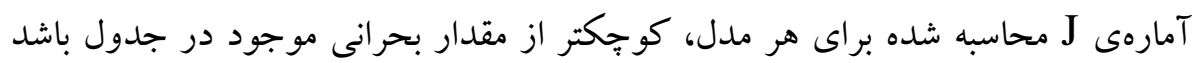

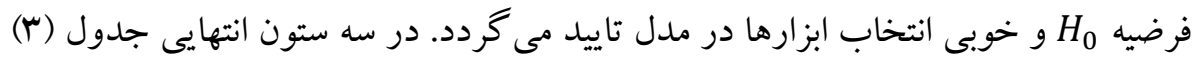
به ترتيب آماره J خروجى نرم افزار، آماره J مدل و آماره J لبحرانى آمده است. همانطور

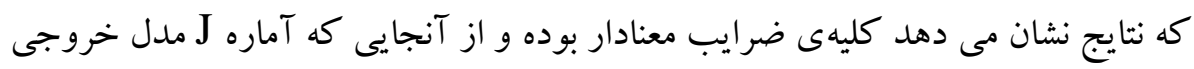

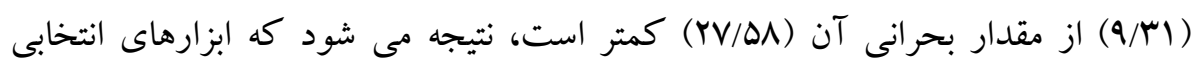


مناسب بودهاند. ضريب مربوط به درصد سهم رشد حجم يول (M1) در اين مدل كه از تابع مطلوبيت با ريسك گريزى نسبى ثابت استفاده شده است برابر به// • مى باشد؛ كه اين موضوع گوياى آن است كه خانو ارهاى ايرانى ترجيح مىدهند كه بخش قابل مل ملاحظهاى

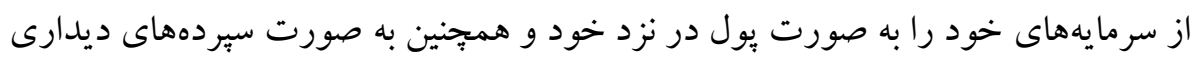

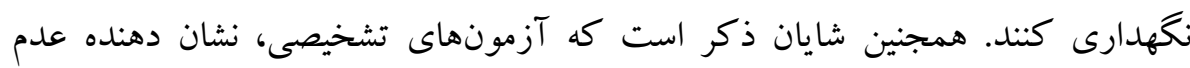

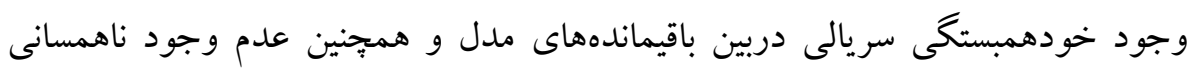
واريانس در بين جملات اختلال مىباشد. نتايج بهترين مدل تخمينى به همراه مقادير اوليه و ابزارهاى مناسب براى معادله اول يا

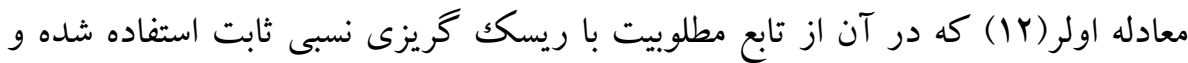

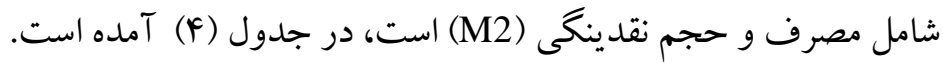

جدول ^. نتايج تخمين مدل اول با وجود حجم نقدينكى (يول و شبه بول) (M2)

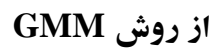

\begin{tabular}{|c|c|c|c|c|c|c|}
\hline 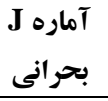 & آماره J & آماره J خروجى افزار & $\gamma$ & $\boldsymbol{\epsilon}$ & $\boldsymbol{\delta}$ & $\begin{array}{l}\text { مقادير اوليه } \\
(\gamma, \boldsymbol{\epsilon}, \boldsymbol{\delta})\end{array}$ \\
\hline 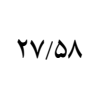 & $9 / \Gamma 1$ & $\cdot / 499$ & $\begin{array}{l}r Y / Y q \\
*(\Delta / 9 \Lambda)\end{array}$ & $\begin{array}{c}\cdot / \mu F \\
*(I r / V q)\end{array}$ & $\begin{array}{l}\cdot / F T \\
*(Y / r \Lambda)\end{array}$ & $(1 / 1, V / \cdot \bullet \Delta / \Gamma)$ \\
\hline \multicolumn{7}{|c|}{ آزمونهاى تشخيصى } \\
\hline \multicolumn{3}{|c|}{ مقداراحتمال(P_value) } & \multicolumn{3}{|c|}{ مقدار آماره } & آزمون \\
\hline \multicolumn{3}{|c|}{$\cdot / \mathrm{r} \Lambda$} & \multicolumn{3}{|c|}{ IN/Ar } & خودهمبستگى سريالى \\
\hline \multicolumn{3}{|c|}{$\cdot / F V$} & \multicolumn{3}{|c|}{$1 / 49$} & ناهمسانى واريانس \\
\hline
\end{tabular}

" مقادير مربوط به آزمون t در سطح معنى دارى هـ درصد

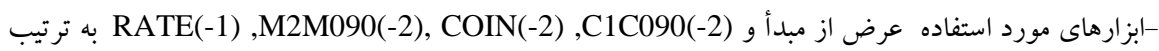
وقفه دوم نسبت مصرف در دو دوره متوالى به قيمت بايه •9، وقفه دوم بازده طلا (سكه)، وقفه دوم نسبت حجم

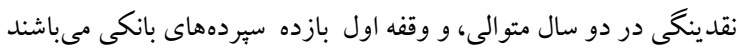

از نتايج مندرج در جدول (F) بيداست كه كليهى ضرايب معنادار بوده و از آنجايى كه

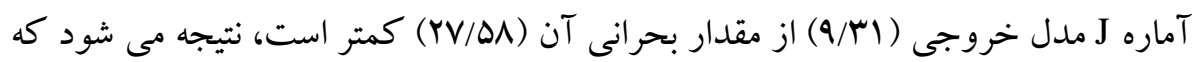
ابزارهاى انتخابى مناسب بودهاند. ضريب مربوط به درصد سهم رشد حجم نقدينخى (M2) 
برابر بF/ • مى باشد. همجنين خودهمبستخى سريالى و ناهمسانى واريانس بين باقيماندههاى

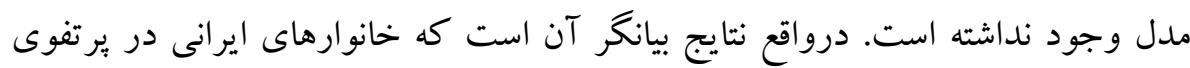

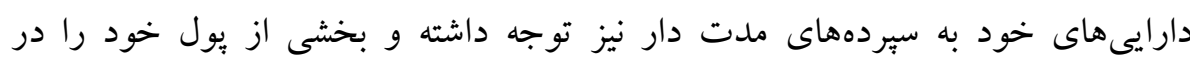

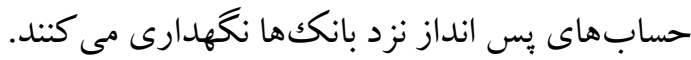

ץ-r ب. برآورد معادلات اولر و تخمين ضريب سهم تراز ثولى در تابع مطلوبيت

\section{خانوارها با ترجيحات باز تشتى}

دومين مدلى كه در اين يزوهش براى تخمين تعيين سهم تراز يولى در تابع مطلوبيت

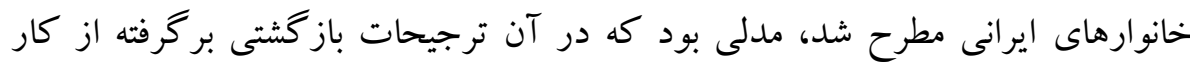

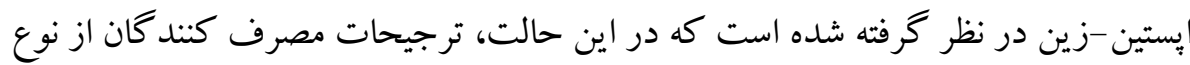

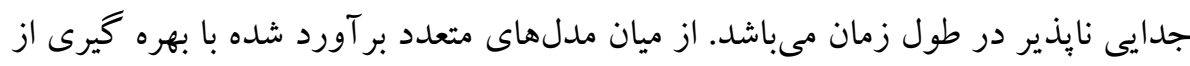
متغيرهاى ابزارى و مقدار دهى اوليه، نتايج بر آورد ضرايب بهترين مدل براى معادله اولر

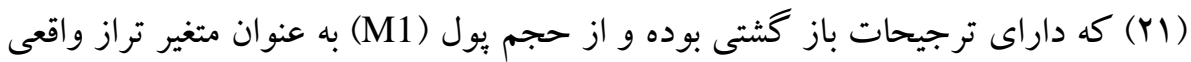
يول در آن استفاده شده است، در جدول (ه) آمده است.

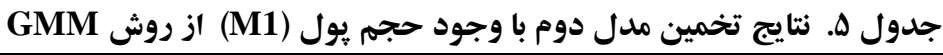

\begin{tabular}{|c|c|c|c|c|c|c|c|}
\hline 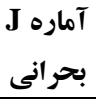 & آملاره Jل & آماره J خروجى افزار & $\boldsymbol{\theta}$ & $\gamma$ & $\boldsymbol{\epsilon}$ & $\delta$ & $\begin{array}{l}\text { مقادير اوليه } \\
(\boldsymbol{\kappa}, \boldsymbol{\gamma}, \boldsymbol{\epsilon}, \boldsymbol{\delta})\end{array}$ \\
\hline$r y \cdot r G$ & $9 / \mu_{4}$ & $\cdot / 49$ & $\begin{array}{c}1 / \Delta \\
*(\mid r / r V)\end{array}$ & $\begin{array}{c}W V \\
*(Y Y / A V)\end{array}$ & $\begin{array}{l}\cdot / r) \\
*(r \mid / V q)\end{array}$ & $\begin{array}{l}\cdot / \Delta 1 \\
*(Y / \cdot Y)\end{array}$ & $\begin{array}{c}(\cdot / f) \\
(\cdot / \cdot 6) / \cdot 61 / f\end{array}$ \\
\hline \multicolumn{8}{|c|}{ آزمونهاى تشخيصى } \\
\hline \multicolumn{3}{|c|}{ مقداراحتمال(P_value) } & \multicolumn{3}{|c|}{ مقدار آماره } & \multicolumn{2}{|c|}{ آزمون } \\
\hline \multicolumn{3}{|c|}{.$/ 99$} & \multicolumn{3}{|c|}{$F \Delta / \mu$} & \multicolumn{2}{|c|}{ خو دهمبستَّى سر يالى } \\
\hline \multicolumn{3}{|c|}{$\cdot|4|$} & \multicolumn{3}{|c|}{$1 / \Delta F$} & \multicolumn{2}{|c|}{ ناهمسانى واريانس } \\
\hline
\end{tabular}

*قادير مربوط به آزمون t در سطح معنى دارى هـ درصد

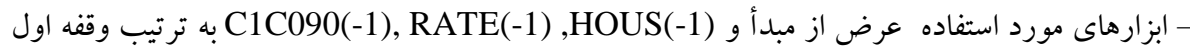

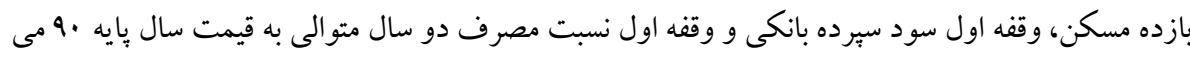


آماره t ضرايب برآوردى نشانگر آن است كه كليهى ضرايب در سطح اطمينان هو

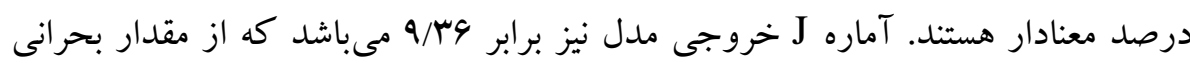

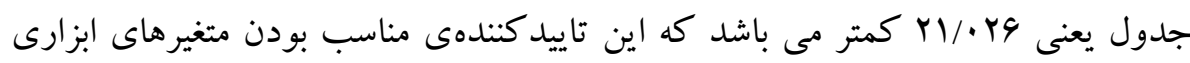

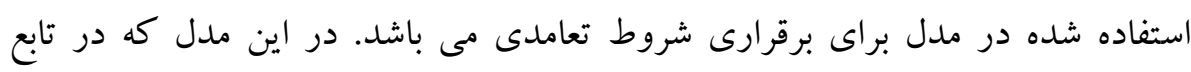
مطلوبيت آن از ترجيحات باز گشتى استفاده شده است، ضريب رشد حجم يول (M1) در تابع مطلوبيت خانوار است، برابر اس// مى باشد. نتايج آزمونهاى

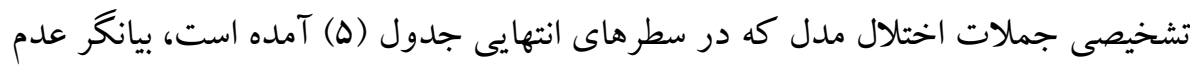
وجود ناهمسانى واريانس در بين جملات باقيمانده مدل و عدم وجود خودهمبستكى دربين

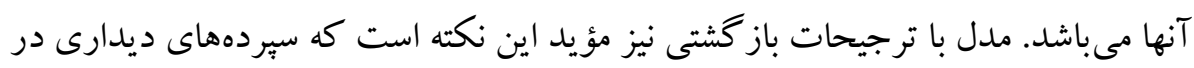

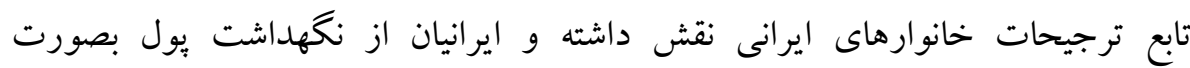

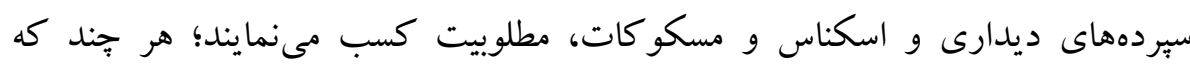
مقدار آن جشمخير نمىباشد.

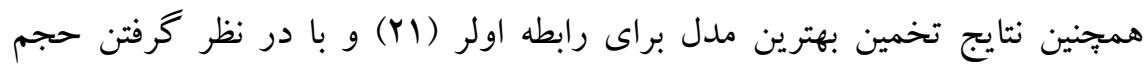

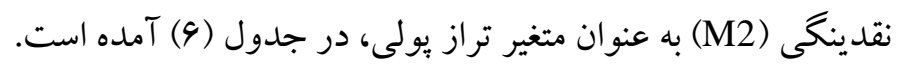

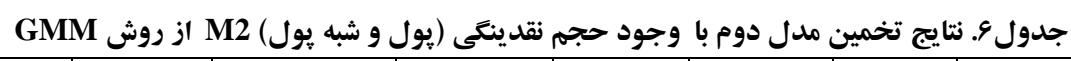

\begin{tabular}{|c|c|c|c|c|c|c|c|}
\hline 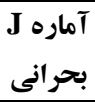 & آماره J & نآماره آل خروجى افزار & $\boldsymbol{\theta}$ & $\gamma$ & $\epsilon$ & $\delta$ & $\begin{array}{l}\text { مقادير اوليه } \\
(\kappa, \gamma, \epsilon, \delta)\end{array}$ \\
\hline$r y / . r 9$ & $9 / r^{4}$ & $\cdot / 49$ & $\begin{array}{c}r / \wedge V \\
*(I Y / Y q)\end{array}$ & $\begin{array}{c}91 / 91 \\
*(1 / / 4 V)\end{array}$ & $\begin{array}{c}\cdot / 9 Y \\
*(11 / T V)\end{array}$ & $\begin{array}{c}\cdot / r \cdot \\
*(r / \cdot 9)\end{array}$ & $\begin{array}{c}(\cdot / f) \\
(\cdot / \cdot 6) / \cdot 61 / f\end{array}$ \\
\hline \multicolumn{8}{|c|}{ آزمونهاى تشخيصى } \\
\hline \multicolumn{3}{|c|}{ مقدار احتمال(P_value) } & \multicolumn{3}{|c|}{ مقدار آماره } & \multicolumn{2}{|c|}{ آزمون } \\
\hline \multicolumn{3}{|c|}{$\cdot / Q F$} & \multicolumn{3}{|c|}{$r \cdot / \mu q$} & \multicolumn{2}{|c|}{ خودهمبستخى سريالى } \\
\hline \multicolumn{3}{|c|}{$\cdot / A V$} & \multicolumn{3}{|c|}{$1 / 4 F$} & \multicolumn{2}{|c|}{ ناهمسانى واريانس } \\
\hline
\end{tabular}

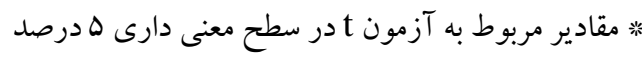

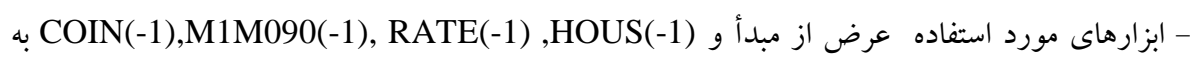

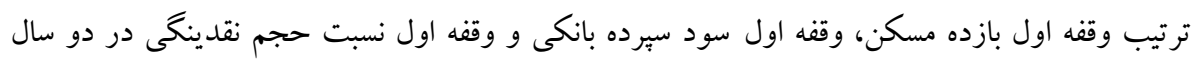

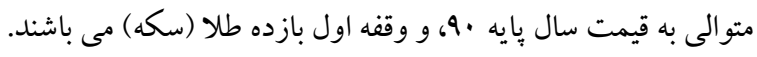


نتايج جدول 9 گوياى آن است كه ضرايب بر آوردى در سطح اطمينان هو درصد معنادار بوده و مقدار آماره J مدل نيز برابر 4س/9 شده است كه مقدار آن از آماره بحرانى جدول يعنى צY/Y كمتر است؛ اين موضوع نشان دهنده آن است كه متغيرهاى ابزارى مناسب بودهاند. ضريب € كه نشان دهندهى سهم رشد حجم نقدينكى (M2) در تابع مطلوبيت خانوار است، برابر و / • مىباشد.آزمونهاى تشخيصى مربوط به جملات اختلال نيز نشان

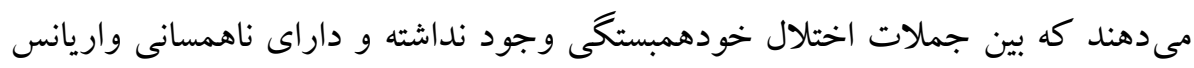
نيستد. نتايج تعيين سهم حجم نقدينگى در مدل با تابع مطلوبيت باز گشتى نيز گوياى

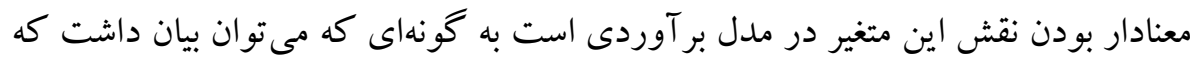

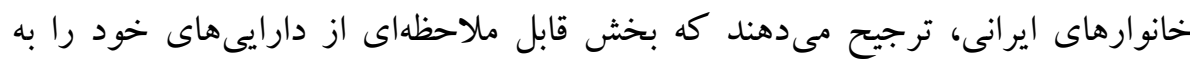

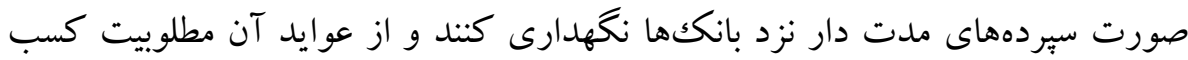
نمايند.

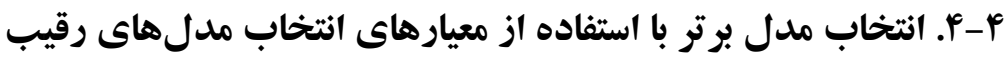

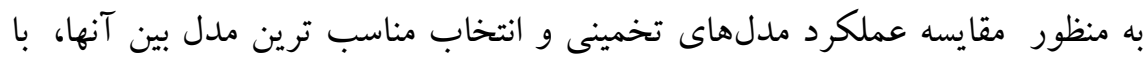

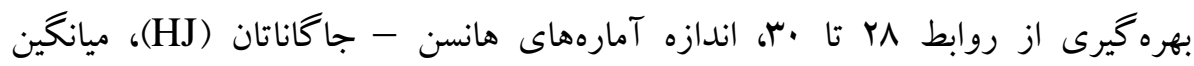
قدرمطلق خطاها (MAE) و ميانگين مجموع مجذور خطاها (MSE) براى هر جهار مدل تخمين زده شده، در جدول (V) آمده است.

جدول Y. نتايج معيارهاى انتخاب مدل برتر در بين مدل الهاى رقيب

\begin{tabular}{|c|c|c|c|}
\hline MSE & MAE & آماره HJ & نام مدل \\
\hline $10 / 9$ & . /qVa & $\cdot / I V \cdot \Lambda I V$ & مدل اول با M1 \\
\hline $9 / 4$ & $\cdot / \mu V V$ &.$/ .94 V$ & مدل اول با M2 \\
\hline$M F / Q$ & $\cdot / \Delta \wedge r$ &.$/ 194119$ & مدل دوم با M1 \\
\hline $1 \cdot / 0$ &.$/ 44$. & $\cdot / 1 \cdot 1 V \Delta V$ & مدل دوم با M2 \\
\hline
\end{tabular}

منبع: يافتهاى يُزوهش 
نتايج جدول (V) نشان مىدهد كه در بين جهار مدل بر آورد شده، مدل با ترجيحات

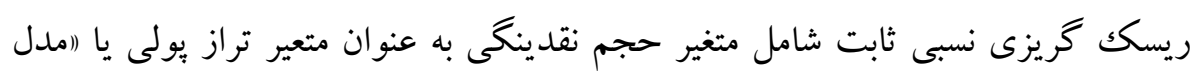

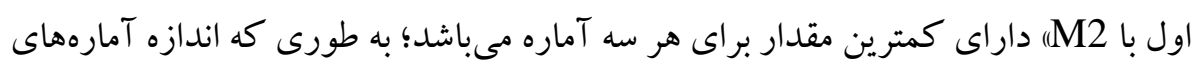

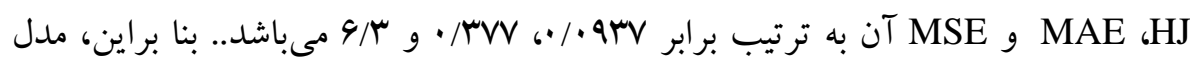

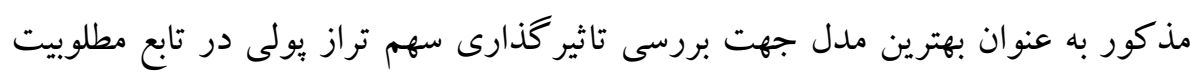

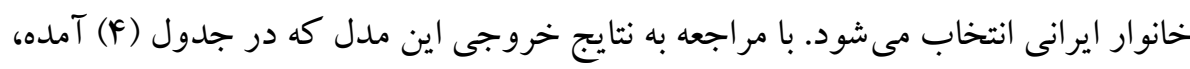

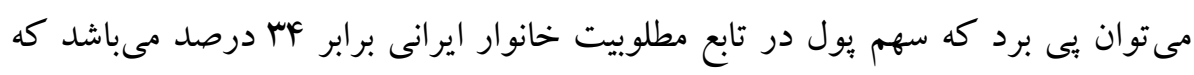
قابل ملاحظه است.

\section{ه. نتيجه گيرى وييشنهادها}

يكى از مهمترين متغيرهاى اقتصادى، تراز يولى است كه لازمست دهادها در مدلسازىهاى مختلف به آن توجه شود. از اين رو در اين مقاله سعى شد تا با توسعه مدلهاى

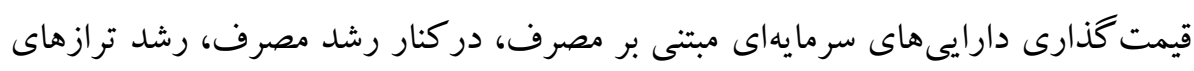

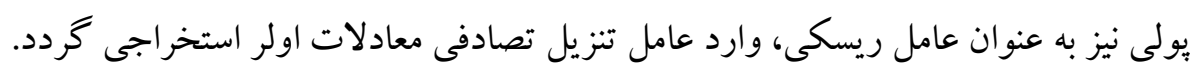

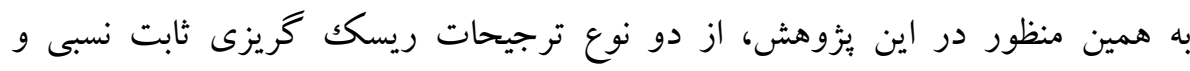

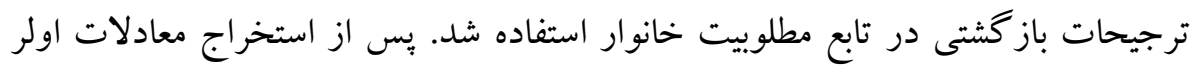

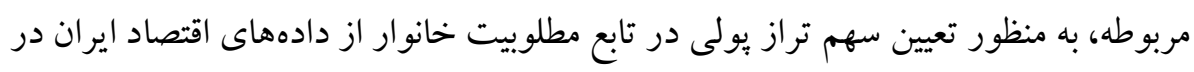

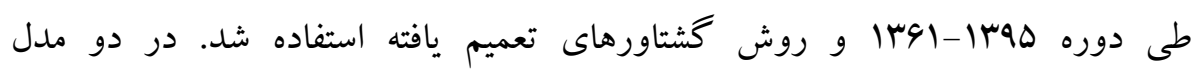
استخراجى، از سرىهاى زمانى حجم يول (M1) و حجم نقدينگى (مجموع بول و شبه

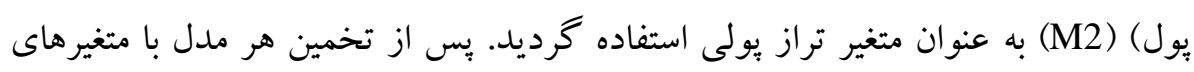

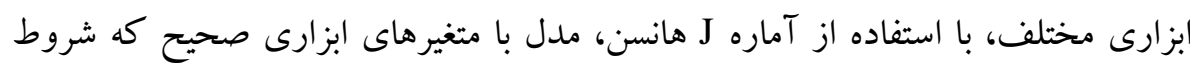
تعامدى را برقرار مىسازند، انتخاب شد. يافتها گوياى آن است كه سهم متغير يولى (M1)

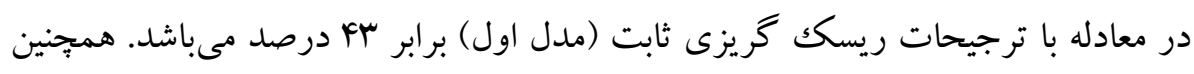
سهم متغير يولى (M2) در مدل مذكور برابر MF درصد است. در هر دو تخمين، كليه 
ضرايب از نظر آمارى معنا دار بوده و آزمونهاى تشخيصى نيز، صحت بر آوردها را تاييد

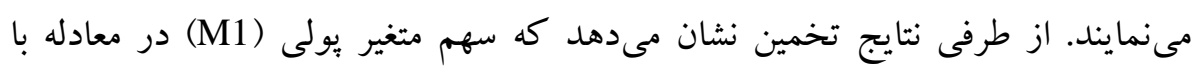

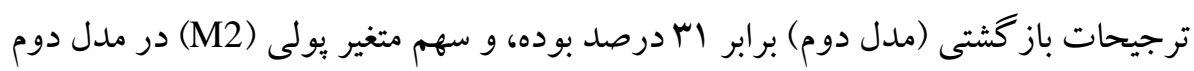
برابر بو درصد است. در اين مدل نيز، ضرايب معنادار بوده و آزمونهاى تشخيصى مربوط

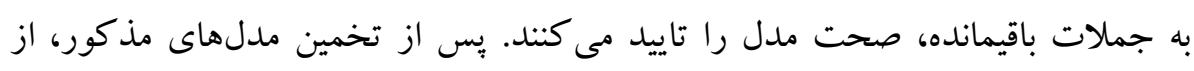

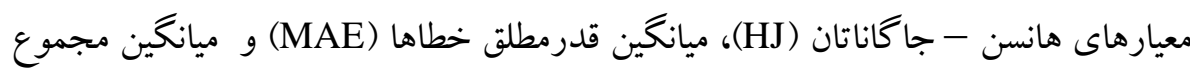
مجذور خطاها (MSE) براى انتخاب مدل برتر در بين مدلهاى برازش شده، استفاده گرديد كه مدل با ريسك گريزى نسبى ثابت و حاوى متغير M2 داراى كمترين مقدار

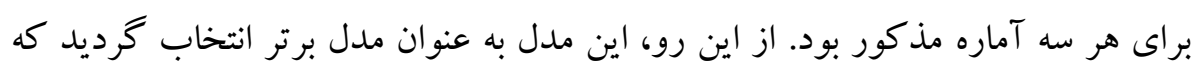
نشان دهنده آن است كه سهم متغير تراز بولى (حجم نقدينكى) در تابع مطلوبيت خانوارهاى ايرانى در طى دوره مورد بررسى برابر بF درصد مىباشد كه قابل ملاحظه

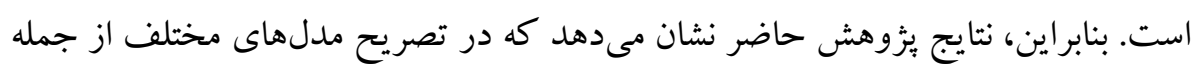

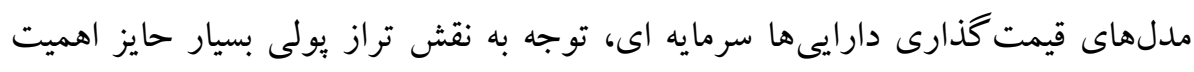

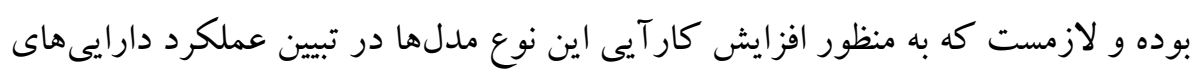

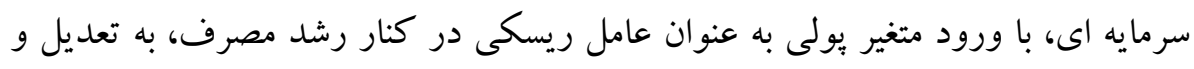

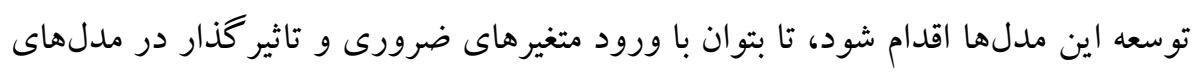
قيمت گذارى دارايىهاى سرمايه ای، ضمن افزايش دقت مدلها و اتكاء بيشتر به نتايج آنها، منابع مالى به نحو مناسب ترى هدايت شوند. در بسيارى از ئزوهشها كه از مدلهاى

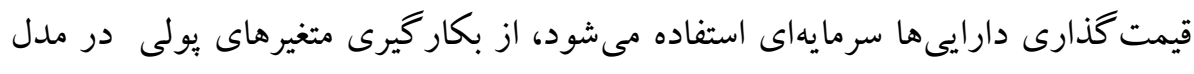
غفلت شده، واين موضوع مى تواند به نتايج تورش دارى منجر شود. لذا لازمست محققانى كه در كار خود از مدلهاى CCAPM بهره مىبرند به متغيرهاى بولى نيز توجه ويزهاى تورسى

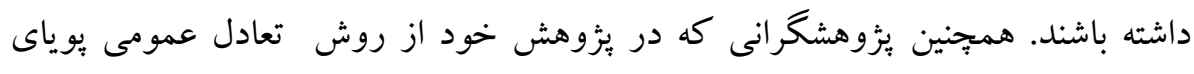
تصادفى استفاده مى كنند، لازمست در بخش ترجيحات خانوار، متغير تراز يولى نيز به عنوان

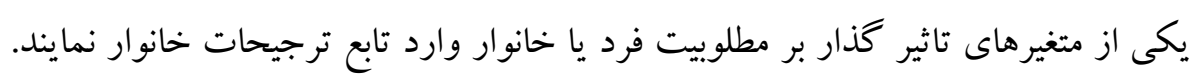


همجينين با توجه به قابل ملاحظه بودن ضريب متغيرهاى ترازيولى در تابع ترجيحات

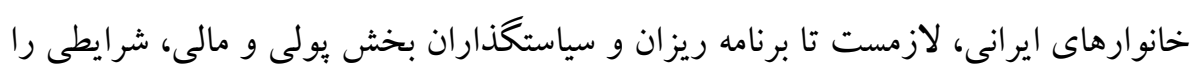

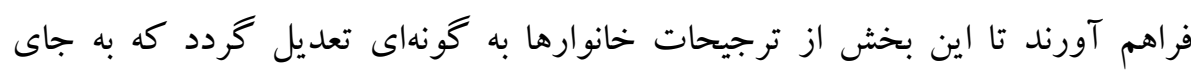

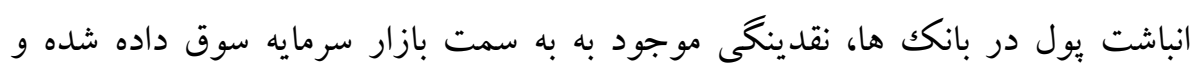

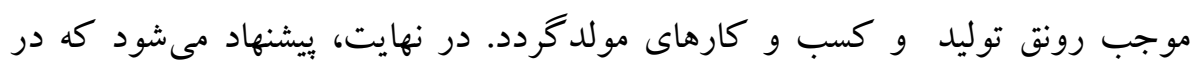

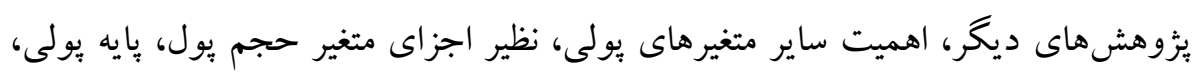

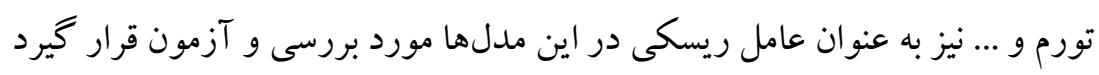




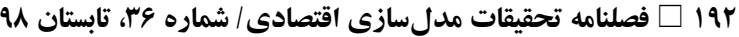

منابع و مآخذ

- Adegboye Abidemi (2017), The consumption-oriented capital asset price model in the Nigerian stock exchange, CBN Journal o Applied Statistics, 8(2).117-140.

- Balvers J. Ronald, and Huang Dayong. (2009). Money and the C-CAPM, Journal of Financial and Quantitative Analysis, 44(2), 337-368.

- Breeden, Douglas T. (1979). An intertemporal asset pricing model with stochastic consumption and investment opportunities, Journal of Financial Economics, 7, 265-296.

- Brock, W. A. (1974). Money and growth: The case of long run perfect foresight. International Economic Review, 15, 750-777.

- Campbell Y. John, Giglio Stefan, Polk Christopher and Turleky (2018). An intertemporal CAPM with stochastic volatility, , Journal of Financial Economics, 128, 207-233.

- Cochrane, J. (2008). A Cross-Sectional Test of an Investment-Based Asset Pricing Model. Journal of Political Economy, 104, 572-621.

- Epstein, L. and Zin, S. (1991). Substitution, Risk Aversion and the Temporal Behavior of Consumption and Asset Returns: An Empirical Analysis. Journal of Political Economy, 99, 263-286.

- Epstein, Larry G, Zin. (1989). Substitution, Risk aversion and the temporal behavior of consumption and asset returns: A Theorical Framework. Econometrica, 57(4), 937-969.

- Fama, E. F., and K. R. French. (1996). Multifactor Explanations of Asset Pricing Anomalies. Journal of Finance, 51, 55-84.

- Froogh Nazhad H and Mirzaei M. (1392). Investigating the relationship between risk and return: Comparing the traditional capital asset pricing model with the pricing model of capital-based consumption assets, Journal of Securities Exchange, 6(23), 51-76.

- Gomes, J., L. Kogan, and M. Yogo. (2009). Durability of output and expected stock returns. Journal of Political Economy, 117, 941-989.

- Gu, L., and D. Huang. (2013). Consumption, money, intratemporal substitution, and cross-sectional asset returns. Journal of Financial Research, 36, 115-146.

- Hansen, Lars Peter, \& Singleton, Keneth J. (1982). Generalized instrumental variables estimation of nonlinear rational expectations models. Econometrica, 50, 1269-1286.

- Izadkhasti Hojjat (1397). Analyzing the Impact of Monetary Policy in a Dynamic General Equilibrium Model: Money in Utility Function Approach, Journal of Economic Modeling Research, 8(31),71-101. 
- Jagannathan, R., and Y. Wang. (2007). Lazy investors, discretionary consumption, and the cross-section of stock returns. Journal of Finance, 62, 1623-1661

- Kan Raymond, and Robotti Cesare. (2009). Model Comparison Using the Hansen-Jagannathan Distance. The Review of Financeial Studies, 22(9), 3449-3490.

- Kocherlakota, N., and L. Pistaferri. (2009). Asset pricing implication of Pareto optimality with private information. Journal of Political Economy, 117, 555-590.

- Obstfeld. M., and K. Rogoff. (1996). Foundations of international macroeconomics. MIT Press.

- Lettau, M., and S. Ludvigson. (2009). Euler equation errors. Review of Economic Dynamics, 12, 255-283.

- Lioui, A., and P. Maio. (2014). Interest rate risk and the cross-section of stock return. Journal of Financial and Quantitative Analysis, 49(2), 83511.

- Liu Weinmin, Luo Di, and Zhao Huainan, (2016), Transaction Costs, Liquidity Risk, and the CCAPM. Journal of Banking \& Finance, 63, 126145 .

- Lucas, Robert E., Jr. (1978). Asset prices in an exchange economy. Econometrica, 46, 1429-1445.

- Lucas E. Robert and Stokey L. Nancy. (1987). Money and Interest in a Cash-in-Hand Economy. Econometrica, Econometric Society, 55(3), 491-513.

- Lustig, H., and S. Van Nieuwerburgh. (2005). Housing collateral, consumption insurance, and risk premia: An empirical prespective. Journal of Finance, 60, 1167-1219.

- Miralles Quiros Maria, Miralles Quiros Josea, and Oliveira Celia. (2017). The role of Liquidity in asset pricing: the special case of the Portuguese Stock Market. Journal of Economics, Finance and Administrative Sciense, 22(43), 191-206.

- Maio Paulo.(2018). Does inflation explain equity risk premia?Available at SSRN: https://ssrn.com/abstract=3097493.

- Maio Paulo, Silva C. Andre. (2018). Asset pricing implications of new evidence. Available at SSRN: https://ssrn.com/abstract=2388879

- Mehra, Rajnish, \& Edward C Prescott, E. C. (1985). The equity premium: A puzzle. Journal of Monetary Economics, 15, 145-161.

- Merton, R. C. (1971). Optimal consumption and portfolio rules in a continuous-time model. Journal of Economic Theory, 3, 373-413.

- Mohammadzadeh Azam, Shahyaki tash Mohammad nabi, Roshan Reza (1395), Adjusted Consumption Capital Asset Pricing Model, According 
to the Marshall Preferences (Case Study: Iran), Journal of Economic Modeling Research, 7(25),7-22.

- Parker, J., and C. Julliard. (2005). Consumption risk and the cross section of expected returns. Journal of Political Economy, 113, 185-222.

- Savov, A.. (2011). Asset pricing with garbage. Journal of Finance, 66, 177-201.

- Sidrauski, Miguel. (1967). Rational choice and patterns of growth in a monetary economy. American Economic Review, 57, 534-544.

- Weil, P. (1989). The equity premium puzzle and the risk-free rate puzzle. Journal of Monetary Economics, 24, 401-421.

- Weil, P. (1990). Nonexpected Utility in Macroeconomics, Quarterly Journal of Economics, 105, 29-42.

- Yogo, M. (2006). A consumption-based explanation of expected stock returns. Journal of Finance, 61, 539-580.

- Zhang Lu. (2017). the Investment CAPM. European Financial Management, 9999(9999), 1-59. 


\title{
Investigating the Role of real Money Balances in Households' Preferences function in the Framework of the Assets Pricing Models (M-CCAPM): Case study of Iran
}

\author{
Reza Roshan ${ }^{1}$
}

Received: $21 / 12 / 2018$

Accepted: 23/06/2019

\begin{abstract}
In this paper, we try to develop and modify the basic model of the consumption-based capital asset pricing model by adding the growth in real money balances rate as a risk factor in the household's utility function as (MCCAPM). For this purpose, two forms of utility function with constant relative risk aversion (CRRA) preferences and recursive preferences have been used such that M1 and M2 are considered as inputs in the utility function. After estimating the systems of Euler equations using generalized moments method, MSE, MAE, and HJ criteria were used to select the most suitable model for estimating the share of variable of real money balance. The above criteria show that the model with the input of liquidity (M2) and preferences with constant relative risk aversion is the most appropriate model. The results indicate that the share of real money balance in the utility function of Iranian households is statistically significant and is about 34\%. Therefore, considering the contribution of the monetary variable to the utility function which is relatively significant, it is emphasized on its entry into the utility functions used in asset pricing models.
\end{abstract}

Keywords: Consumption-Based Capital Asset Pricing Models, Real Money Balance, Liquidity, Euler Equations, GMM.

JEL Classification: C52, E32, E50, G12.

1. Assistant Professor of Economics, Faculty of Humanities, Persian Gulf University, (Corresponding Author), Email:re.roshan@pgu.ac.ir 